\title{
Optimal Pattern Synthesis of Thinned and Non-Uniformly Excited Concentric Circular Array Antennas using Hybrid GSA-PSO Technique
}

\author{
Rajesh BERA ${ }^{1}$, Krishanu KUNDU ${ }^{2}$, Narendra Nath PATHAK ${ }^{3}$ \\ ${ }^{1}$ Dept. of ECE, Madanapalle Institute of Technology \& Science, Andhra Pradesh, India \\ ${ }^{2}$ Dept. of ECE, Dronacharya College of Engineering, Gurugram, India \\ ${ }^{3}$ Dept. of ECE, Dr. B .C. Roy Engineering College, Durgapur, India
}

rajeshkiit12@gmail.com,krishanukundu08@gmail.com,narendra.pathak@rediffmail.com

Submitted November 17, 2018 / Accepted April 25, 2019

\begin{abstract}
Side Lobe Level (SLL) is considered as the most significant array pattern parameter as it helps in reducing surrounding noise and interference. As higher SLL value results in higher wastage of power in undesired direction, transmitters of wireless communication systems face serious problems. In this paper, the optimal design of seven different sets of concentric circular antenna arrays (CCAAs) of isotropic antenna has been represented with the goal of maximum reduction in SLL. Optimal pattern synthesis of the proposed arrays has been executed by optimizing the normalized current distributions of array elements having fixed inter-element spacing. In present

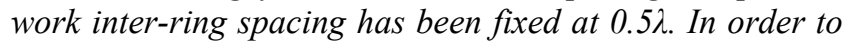
achieve low SLL in the radiation pattern of the optimized array antenna, many conventional optimization methods have been proposed in last few decades for handling complex, non-differentiable, discontinuous and highly nonlinear array factor. To deal with the problems of premature convergence (fall into local optima) feature of gravitational search algorithm (GSA) and particle swarm optimization (PSO) has been merged. In high-dimensional space, gravitational search algorithm hybridized with particle swarm optimization (GSA-PSO) is considered while preserving the fast converging property of them. Numerical results in the present text assume the pattern synthesis of thinned array and non-uniformly excited array for seven different sets of CCAA geometries. An exhaustive simulation results are presented and the radiation pattern performances are analyzed. As compared with conventional optimization techniques like GSA and PSO, hybrid GSAPSO technique outperforms with the goal of maximum SLL suppression.
\end{abstract}

\section{Keywords}

Concentric circular antenna array, Gravitational Search Algorithm (GSA), Particle Swarm Optimization (PSO), Side Lobe Level (SLL), thinning, Gravitational Search Algorithm hybridized with Particle Swarm Optimization (GSA-PSO)

\section{Introduction}

To meet the demand for long-distance communication, it is necessary to design antennas with very high directive (high gain) characteristics. This can be accomplished by increasing the electrical size of the antenna [1]. The best way to enlarge the dimensions of the antenna is to form an assembly of radiating elements in electrical and geometrical configuration where field patterns of individual elements are necessarily constructive or additive in the desired direction and destructive in the other directions. This arrangement provides very low Side Lobe Levels (SLLs) as well as very high directive pattern. The radiation pattern of array antenna can be electronically controlled or steered over the best signal path by adjusting the number of elements, the inter-element spacing, their excitation coefficients, their relative phases, the geometrical configuration of the overall array (linear, circular, elliptical etc.) and the relative pattern of the individual elements. Many synthesis methods are concerned with SLL while preserving the gain of the main beam [2-11].

A linear array [12] has high directivity and it can form the narrowest main-lobe in a given direction. But the problem is that it does not perform efficiently in all azimuthal directions. Directional patterns synthesized with a circular array [3], [13] can be electronically rotated in the plane of the array without a considerable change of the beam shape. This happens because a circular array does not have edge elements. However, the circular array pattern has no nulls in the azimuthal plane. However, the array pattern should have several nulls in the azimuthal plane for smart antenna applications [14], [15]. Concentric circular antenna array (CCAA) [16], [17] comprises many concentric circular rings of different radius. It has many advantages compared with other planar array geometries like linear array and rectangular array. CCAA has become widespread in wireless and mobile communications and have been applied extensively to radar, sonar and satellite communications systems [18], [19] due to its flexibility in beam pattern synthesis, spreading coverage area, efficient spectrum utilization, less mutual coupling sensitivity, increasing channel 
capacity and the frequency invariant characteristics. Array elements in Uniform CCAA (UCCAA) [20] are uniformly excited and the spacing between two adjacent elements in each ring is kept fixed to half of the wavelength. The SLL drop is about $-17.5 \mathrm{~dB}$ in the UCCAA with uniform excitations.

Array thinning involves the removal (switching off) of some radiating elements from a uniformly spaced or periodic array antenna to generate a pattern with low SLL. In this method, the locations of the elements are fixed and all the elements have two states either "on"(active) or "off"(removed) depending on whether the element is connected to the feed network or not. All the active elements are fed with equal amplitude currents, while the remaining elements are turned off. In the "off" state, either the element is passively terminated to a matched load or open circuited. It is equivalent to removal of elements from the array if there is no coupling between them. The main objectives of array thinning are the reduction of cost, weight and power consumption without degradation of array performance. There are many published articles [21-24] dealing with the synthesis of array thinning.

Evolutionary optimization techniques have greater potential to solve complex engineering hitches. Various novel methods and hybridization of two different conventional algorithms have been used to achieve optimal array pattern. There are several disadvantages of classical optimization methods [25]. Thus, it is necessary to develop an efficient and robust optimization method. There are various evolutionary optimization techniques such as genetic algorithm (GA) [26-29], simulated annealing (SA) [30], gravitational search algorithm (GSA) [31-34], particle swarm optimization (PSO) [35-40] etc. for optimization of complex, discontinuous and non-differentiable array factor of the antenna array.

In GSA-PSO, the next velocity of the particle vector is considered as a fraction of its current velocity added to its weighted acceleration (provided by GSA) and weighted difference between the social/group best particle vector and the present position (provided by PSO). Both of these features are combined together in GSA-PSO [41]. In this paper a hybrid version of GSA and PSO techniques, known as GSA-PSO technique has been presented for optimal beam-forming of various thinned CCAAs and non-uniform CCAAs of isotropic elements. The arrangement of this paper is as follows. Section 2 describes the array factor formulations of the various hybrid arrays (cylindrical and coaxial cylindrical arrays). The objective function (cost function) is also modeled in this section. In Sec. 3, brief explanations of the GSA, PSO and hybrid GSA-PSO are presented. The most promising control parameters that generate the most satisfactory results using evolutionary algorithms are presented in Sec. 4. Section 5 summarized the simulation results of synthesized arrays and discussed. Finally Section 6 concludes the paper with the possible extensions briefly.

\section{Design Equation}

General form of the far-field pattern of an $N$-element array of isotropic elements can be explained as (1) [1].

$$
A F(\theta, \phi)=\sum_{n=1}^{N} I_{n} \exp \left[\mathrm{j}\left(\alpha_{n}+k \mathbf{R}_{n} \cdot \mathbf{a}_{\mathrm{r}}\right)\right]
$$

where excitation coefficient of the $n^{\text {th }}$ element is denoted by $I_{n}$; wave number is denoted by $k(=2 \pi / \lambda) ; \alpha_{n}$ is the relative phase and $\mathbf{R}_{n}$ is the position vector of the $n^{\text {th }}$ element; $\mathbf{a}_{\mathrm{r}}$ is unit vector. General array configuration of CCAA with $M$ concentric rings is shown in Fig. 1, where $r_{m}$ is the radius of the $m^{\text {th }}(m=1,2, \ldots, M)$ ring and the corresponding number of element is $N_{m}$. Far field radiation pattern of a CCAA in $x-y$ plane may be written as [17]:

$$
A F(\theta, \phi)=\sum_{m=1}^{M} \sum_{i=1}^{N_{m}} I_{m i} \exp \left[\mathrm{j}\left(\begin{array}{l}
k r_{m} \sin \theta \cos \left(\phi-\phi_{m i}\right) \\
+\alpha_{m i}
\end{array}\right)\right]
$$

where $I_{m i}$ is the excitation amplitude of the $i^{\text {th }}$ element of the $m^{\text {th }}$ ring

$$
I_{m i}=\left\{\begin{array}{ll}
1 & \text { on } \\
0 & \text { off }
\end{array} .\right.
$$

$k=2 \pi / \lambda ; \lambda$ is the wavelength of electromagnetic wave. Equation (2) may be written as a periodic function of $\theta$ with a period of $2 \pi$ radian if the elevation angle $\phi$ is constant. So, the radiation pattern will be a broadside array pattern. The azimuth angle of the $i^{\text {th }}$ element of the $m^{\text {th }}$ ring is $\phi_{m i} . \phi_{m i}$ and $\alpha_{m i}$ are also obtained from [17] as:

$$
\begin{gathered}
\phi_{m i}=2 \pi\left((i-1) / N_{m}\right), \\
\alpha_{m i}=-K r_{m} \sin \theta_{0} \cos \left(\phi-\phi_{m i}\right)
\end{gathered}
$$

where $\theta_{0}$ is the value of $\theta$ where peak of the main lobe is attained in $\theta \in[-\pi, \pi]$. Normalized power pattern in $\mathrm{dB}$ can be expressed as given in (6).

$$
\begin{aligned}
P(\theta, \phi) & =10 \log _{10}\left[\frac{|A F(\theta, \phi)|}{|A F(\theta, \phi)|_{\max }}\right]^{2} \\
& =20 \log _{10}\left[\frac{|A F(\theta, \phi)|}{|A F(\theta, \phi)|_{\max }}\right] .
\end{aligned}
$$

In order to antenna pattern synthesis, the most important parameter is to produce the objective function that is to be minimized. The objective function "Cost Function" $C F$ may be written as follows:

$$
\begin{aligned}
C F & =W_{\mathrm{F} 1} \times \frac{\left|A F\left(\theta_{m \mathrm{~s} 11}, I_{m i}\right)+A F\left(\theta_{m \mathrm{~s} 12}, I_{m i}\right)\right|}{\left|A F\left(\theta_{0}, I_{m i}\right)\right|} \\
& +W_{\mathrm{F} 2} \times\left|\left(F N B W_{\text {computed }}-F N B W\left(I_{m i}=1\right)\right)\right| .
\end{aligned}
$$

$F N B W$ is the width between the two first nulls on either side of the main beam. Cost function $C F$ is computed only if 


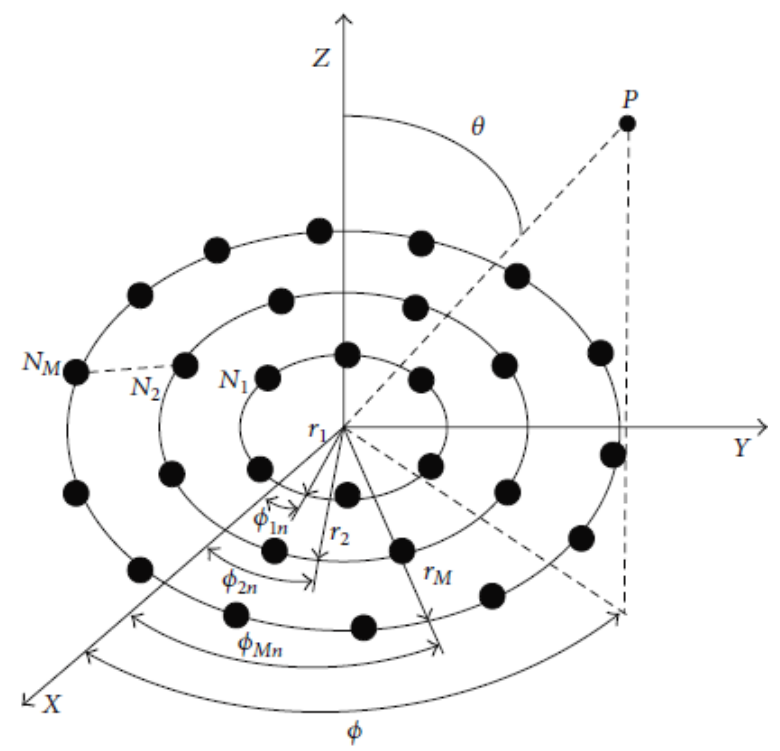

Fig. 1. Geometry of the concentric circular antenna array (CCAA).

$F N B W_{\text {computed }}<F N B W\left(I_{m i}=1\right)$ otherwise the solution is not retained. $W_{\mathrm{F} 1}$ and $W_{\mathrm{F} 2}$ are the weighting factors. $\theta_{m s 1}$ is the angle where the maximum SLL $\left(A F\left(\theta_{m s 1}, I_{m i}\right)\right)$ is attained in the lower band and $\theta_{m \mathrm{sl}} 2$ is the angle where the maximum SLL $\left(A F\left(\theta_{m s 12}, I_{m i}\right)\right)$ is attained in the upper band. $W_{\mathrm{F} 1}$ and $W_{\mathrm{F} 2}$ are weighting constants to control the relative prominence of each term. $F N B W_{\text {computed }}$ and $F N B W\left(I_{m i}=1\right)$ refer to the computed FNBW for the non-uniform excitation case and for the uniform excitation case, respectively. In order to minimize the cost function value, the evolutionary optimization techniques are employed individually. So, the optimization of current excitation weights results in reductions in both SLL and FNBW. All the elements have the same excitation phase of zero degree.

\section{Evolutionary Optimization Methods Engaged}

\subsection{Gravitational Search Algorithm}

GSA [31-34] deals with consideration of particle vectors as objects and their masses are contributing factors to measure performance. Gravitational force is the main reason of attraction between all objects and it results in global movement of objects with lesser weight towards heavier objects. Here better solutions correspond to heavier masses. Lighter masses move faster than heavier masses which justifies the exploitation step. In physics we talk about three types of major masses such as active gravitational mass $\left(M_{\mathrm{a}}\right)$, passive gravitational mass $\left(M_{\mathrm{p}}\right)$ and inertial mass $\left(M_{\mathrm{i}}\right)$. In active gravitational mass $\left(M_{\mathrm{a}}\right)$, an object having high active gravitational mass shows more gravitational field. In passive gravitational mass $\left(M_{\mathrm{p}}\right)$, an object having higher passive gravitational mass senses greater force. Inertial mass $\left(M_{\mathrm{i}}\right)$ focuses on estimation of object's resistivity towards altering its state of motion according to application of force. An object having small inertial mass alters motion more quickly in comparison with the rest.

Position, inertial mass, active gravitational mass and passive gravitational mass are major specification of masses in GSA. Solution for the optimization problem is determined by position of mass as well as a fitness function, which determines gravitational and inertial masses. We can say every bit of mass symbolizes a particular solution.

The algorithm is operated by efficiently regulating gravitational as well as inertial masses. Heaviest mass attracts other masses. This particle having excessive active gravitational mass represents optimum solution. In GSA masses follow two laws such as the law of gravity and the law of motion. According to first law every particle is attracted by other particle so as attraction force is linearly proportionate to multiplication of their masses whereas inversely proportionate to inter element distance denoted by $R . R$ is utilized as $R^{r \text { Power }}(r$ Power $=1)$ as $R$ exhibits greater outcome instead of $R^{2}$ in all trials having benchmark functions [35]. On the other hand, according to the law of motion particle's present velocity is the total of fraction of particle's old velocity along with variation in velocity. Variation in particle's velocity is same as applied force divided by mass of inertia. Here, if we assume a system comprised of $N$ particles having different masses. The $i^{\text {th }}$ particle's position is described as

$$
X_{i}=\left(x_{i}^{1}, \ldots, x_{i}^{d}, \ldots, x_{i}^{n}\right), i=1,2, \ldots, N
$$

where $x_{i}^{d}$ depicts the $i^{\text {th }}$ particle's position in the $d^{\text {th }}$ dimension. For a particular generation cycle $t$, applied force over the $i^{\text {th }}$ particle by the $j^{\text {th }}$ particle is described as:

$$
F_{i j}^{d}(t)=G(t) \frac{M_{\mathrm{p} i}(t) M_{\mathrm{a} j}(t)}{R_{i j}(t)+\varepsilon}\left(X_{j}^{d}(t)-X_{i}^{d}(t)\right) .
$$

Here, at the $t^{\text {th }}$ generation cycle, $M_{\mathrm{a} j}(t)$ denotes the $j^{\text {th }}$ particle's active gravitational mass, same way $M_{\mathrm{p} i}(t)$ is the $i^{\text {th }}$ particle's passive gravitational mass, gravitational constant is $G(t), \varepsilon$ is a constant having small value, and $R_{i j}(t)$ stands for Euclidian distance, i.e. distance between particle $i$ and $j$ and is denoted by (10).

$$
R_{i j}(t)=\left\|X_{i}(t), X_{j}(t)\right\|_{r \text { Norm }}, \quad{ }_{r N o r m} \text { is usually } 2 .
$$

For fulfilling stochastic criteria for the algorithm, we assume that total force which is acting on the $i^{\text {th }}$ particle in the $d^{\text {th }}$ dimension is a randomly weighted sum of $d^{\text {th }}$ components of the forces exerted by other particles. Similarly it is depicted as (11).

$$
F_{i}^{d}(t)=\sum_{j=1, j \neq i}^{N} \operatorname{rand}_{j} F_{i j}^{d}(t)
$$

where rand $_{j}$ denotes a random number within limit $[0,1]$. Hence, by the law of motion, the acceleration of the $i^{\text {th }}$ particle at generation cycle $t$, and in the $d^{\text {th }}$ dimension, $a_{i}^{d}(t)$ is given by (12). 


$$
a_{i}^{d}(t)=\frac{F_{i}^{d}(t)}{M_{i i}(t)}
$$

where $M_{i i}(t)$ stands for the $i^{\text {th }}$ particle vector's inertial mass. Particle's present velocity is the total of fraction of particle's old velocity and change in velocity. So, particle's velocity and its position can be estimated by (13) and (14), respectively.

$$
\begin{gathered}
v_{i}^{d}(t+1)=\operatorname{rand}_{i} \times v_{i}^{d}(t+1)+a_{i}^{d}(t), \\
x_{i}^{d}(t+1)=x_{i}^{d}(t)+v_{i}^{d}(t+1) .
\end{gathered}
$$

From (13), rand $_{i}$ denotes an unvarying random variable in $[0,1]$, which is basically used to give random nature to the search.

After initialization at the beginning, gravitational constant $(G)$ gets reduced in future generation cycles to regulate accuracy in search space. Hence, $G$ can be depicted as in (15)

$$
G=G_{0} \exp \left(-\alpha \cdot\left(\frac{t}{\text { maxGenCycles }}\right)\right) .
$$

Cost function $(\mathrm{CF})$ evaluation calculates gravitational and inertia masses. Particle with heaviest mass is the most efficient one. It means superior particles are having greater attraction capability and they walk rather in slow speed. If we consider equal gravitational as well as inertia mass, map of fitness determines values for masses and accordingly values of gravitational and inertial masses are upgraded.

$$
\begin{gathered}
M_{\mathrm{a} i}=M_{\mathrm{p} i}=M_{\mathrm{i} i}, \text { for } i=1,2, \ldots, N, \\
m_{i}(t)=\frac{f i t_{i}(t)-\operatorname{worst}(t)}{\operatorname{best}(t)-\operatorname{worst}(t)}, \\
M_{i}(t)=\frac{m_{i}(t)}{\sum_{1}^{N} m_{i}(t)} .
\end{gathered}
$$

Here $f i t_{i}(t)$ stands for the $i^{\text {th }}$ particle's fitness value at the $t^{\text {th }}$ generation cycle, whereas worst $(t)$ and $\operatorname{best}(t)$ are well described in (19) and (20), for optimization problem.

$$
\begin{aligned}
\operatorname{best}(t) & =\min _{j \in\{1, \ldots . N\}} f i t_{j}(t), \\
\operatorname{worst}(t) & =\max _{j \in\{1, \ldots . N\}} f i t_{j}(t) .
\end{aligned}
$$

To have a better comparison between exploration and exploitation it is desired to minimize particle population along cycles of generation in (11). So we presume that heavy mass particles exert forces to other particles.

This policy should be handled with care as it results in reduction in exploration power and increment exploration capability. Exploration must be used at the beginning of algorithm for avoidance of the trapping problem. With the advancement of iterations fade in of exploitation and fade out of exploration must take place. As Kbest particles are capable of attracting others, the GSA is well measured by restricting exploration and exploitation.

The initial value related to function for generation cycle is denoted by Kbest and it reduces along with generation cycle. Similarly all particles exert forces primarily and with the progress of generation cycle Kbest is reduced in linear fashion. As a result only one particle will be left at the end to exert force on others. Consequently (11) can be rewritten as (21).

$$
F_{i}^{d}(t)=\sum_{j \in K b e s t, j \neq i} \operatorname{rand}_{j} F_{i j}^{d}(t) .
$$

According to (21), Kbest depicts a set of the first $K$ particles having best value of fitness as well as heaviest masses.

\subsection{Particle Swarm Optimization (PSO)}

The best part of PSO says it does not get trapped on local optima. PSO is capable of handling non-differential objective functions dissimilar to the conventional optimization methods. Life style of swarm of birds is taken into consideration for developing logic behind PSO by Eberhart et al. [39-44]. Concept of PSO revolves around simulation through flocking of birds in space. An objective function is being optimized according to flocking of bird. pbest resembles as best value till is known to each bird (particle) according to their personal experience.

Not only that each particle is familiar with the best value in the group among pbest commonly known as gbest. Generally position of each particle is being modified according to below mentioned information:

- Spacing between pbest and current position.

- Spacing between gbest and current position.

Same as Genetic Algorithm, in Particle Swarm Optimization we assume particle vectors with real coded feature having total population $\left(n_{p}\right)$. Every particle vector is having segments as per requirement of design parameters we ought to optimize. Accordingly, velocities for particle vectors are rewritten as per following equation:

$$
\begin{aligned}
V_{i}^{d}(k+1) & =w \times V_{i}^{d}(k)+C_{1} \times \text { rand }_{1} \times\left(\text { pbest }_{i}^{d}(k)-X_{i}^{d}(k)\right) \\
& +C_{2} \times \text { rand }_{2} \times\left(\text { gbest }^{d}(k)-X_{i}^{d}(k)\right) .
\end{aligned}
$$

Here for the $i^{\text {th }}$ particle in the $k^{\text {th }}$ iteration: $V_{i}^{d}(k)$ stands for velocity; $X_{i}^{d}(k)$ tells the current position; pbest ${ }_{i}^{d}(k)$ stands for personal best of the $i^{\text {th }}$ particle vector; gbest $t_{i}^{d}(k)$ stands for group best of the group in all cases the $d^{\text {th }}$ dimension has been taken into consideration; weighting function is given by $w$; positive weighting factors are $C_{1}$ and $C_{2}$; random numbers $\left(r a n d_{1}, r a n d_{2}\right)$ within limit of 0 and 1 ; We can find modified searching point in the solution space by

$$
X_{i}^{d}(k+1)=X_{i}^{d}(k)+v_{i}^{d}(k+1) .
$$


The particle vector's old velocity is described in the first term of (22). The successive terms are utilized to modify the particle's velocity. Exclusion of these terms forces the particle to fly in without changing direction, till it bangs with the boundary. Basically, inertia constant $(w)$ focuses on inertia characterization for exploring new areas.

\subsection{Backtracking Gravitational Search Algo- rithm Hybridized with Particle Swarm Optimization (GSA-PSO)}

In GSA particle vector's next velocity is treated as portion of its present velocity combined together with its weighted acceleration. The same in PSO can be summarized as weighted divergence among current position and social/group best particle vector. Both these features are combined together in GSA-PSO [41]. In traditional PSO inertia term as well as social/group best term has equivalence with first and third term. Therefore, its position and velocity for the next cycle $(t+1)$ are presented by $(25)$ and (24), respectively.

$$
\begin{aligned}
& v_{i}^{\prime d}(t+1)= \\
& w \times v_{i}^{d}(t)+c_{1} \times a_{i}^{d}(t)+c_{2} \times\left(\text { gbest }^{d}(t)-X_{i}^{d}(t)\right) .
\end{aligned}
$$

For current cycle $(t+1)$, the social/group best particle vector is denoted by gbest $^{d}(t)$.

$$
X_{i}^{\prime d}(t+1)=X_{i}^{d}(t)+v_{i}^{d}(t+1) .
$$

The term associated with the social/group best particle vector is represented by the updated velocity expressions' third term in GSA-PSO. The restriction of the updated position to follow present iteration's social best position makes GSA-PSO to perform better than GSA or PSO as individual. The algorithm can be summarized as:

\section{Step-1:}

Initialization: particle vectors' population is denoted by $\left(n_{p}=150\right)$, dimension for problem to be optimized $(D)$; maximum number of iterations (200); every design parameter's higher and lower limit of boundary. Decrement factor relative to $G$ is denoted by $\alpha$ used in reduction in acceleration simultaneously with the advancement of iteration from global search of initial stage to local search of final stage. This is due to the fact that perturbation property of particles reduces along with the advancement to the local search of final stage. After several trials $\alpha=20$ provides significant results. We take value of $G_{0}$ as $1000 ; \mathrm{rNorm}$ is taken as 2 ; rPower equals to $1 ; \varepsilon$ is considered as 0.0001 ; velocity $=\operatorname{zeros}\left(n_{p}, D\right)$ contributes to maximum outcome of GSA-PSO. $c_{1}=c_{2}=2.05$, helps in achieving better result.

Step-2:

Formulate design parameters' initial particle vectors (D) randomly within proper limits.

Step-3:

Determination of the total population's $C F$ values $\left(n_{p}\right)$.

Step-4:

Determine the best solution particle vector for the entire population.
Step-5:

Revise and update values for $G(t)=G^{\prime}(t)$, best $(t)=\operatorname{best}^{\prime}(t)$, $\operatorname{worst}(t)=\operatorname{worst}^{\prime}(t)$, and $M_{i}(t)=M_{i}^{\prime}(t)$, for $i=1,2, \ldots, n_{p}$; current iteration cycle is denoted by $t$.

Step-6:

Estimation of the sum of forces in distinctive directions.

Step-7:

Particles' velocities and accelerations are to be estimated.

Step-8:

Particles' positions are to be updated.

Step-9:

Repetition of Steps 3 to 8 to be continued till the achievement of stopping criterion.

Step-10:

Ultimately, gbest symbolizes the vector of optimal design parameters $(D)$

\section{Setting of Algorithm Parameters}

Sometimes, the control parameters of GSA, PSO and GSA-PSO techniques are quite sensitive. The parameter values should be carefully chosen which are shown in Tab. 1. The minimum $\mathrm{CF}$ values against iteration cycles are recorded to get the convergence profiles for the algorithms.

\begin{tabular}{|c|c|c|c|}
\hline Parameters & GSA & PSO & GSA-PSO \\
\hline Population size & 150 & 150 & 150 \\
\hline Iteration cycle & 200 & 200 & 200 \\
\hline$\alpha$ & 20 & - & 20 \\
\hline$G_{0}$ & 1000 & - & 1000 \\
\hline$r$ Norm & 2 & - & 2 \\
\hline$r$ Power & 2 & - & 2 \\
\hline$\varepsilon$ & 0.0001 & - & 0.0001 \\
\hline$c_{1}$ & - & 2.05 & 2.05 \\
\hline$c_{2}$ & - & 2.05 & 2.05 \\
\hline$v_{i}^{\min }$ & - & 0.01 & 0.01 \\
\hline$v_{i}^{\max }$ & - & 1.0 & 1.0 \\
\hline$w_{\min }$ & - & 0.4 & 0.4 \\
\hline$w_{\max }$ & - & 1.0 & 1.0 \\
\hline
\end{tabular}

Tab. 1. Control parameters of algorithms.

\section{Computational Results and Discus- sions}

Two design examples are being presented based on distribution pattern of the normalized excitation coefficients of array elements. In the first example, various evo- 
lutionary optimization techniques have been applied for the optimal thinning of CCAA of different rings to reduce the SLL values.

Same optimization techniques are used in the second example where reduction of maximum SLLs has been done by optimizing non-uniform distribution of excitation amplitudes of the arrays of same size.

In both examples we consider optimal design of different sets of concentric circular antenna arrays arranged in a format like array of 2 rings having $(6,12)$ elements called array-1, array of 3 rings having $(6,12,18)$ elements called array-2, array of 4 rings having $(6,12,18,24)$ elements called array-3, array of 5 rings having $(6,12,18,24$, $30)$ elements called array- 4 , array of 6 rings having $(6,12$, $18,24,30,36)$ elements called array-5 and array of 7 rings having $(6,12,18,24,30,36,42)$ elements called array-6, respectively, with fixed inter-ring spacing of $0.5 \lambda$. Interelement spacing can be calculated for each ring of all the array formats using MATLAB codes presented below:

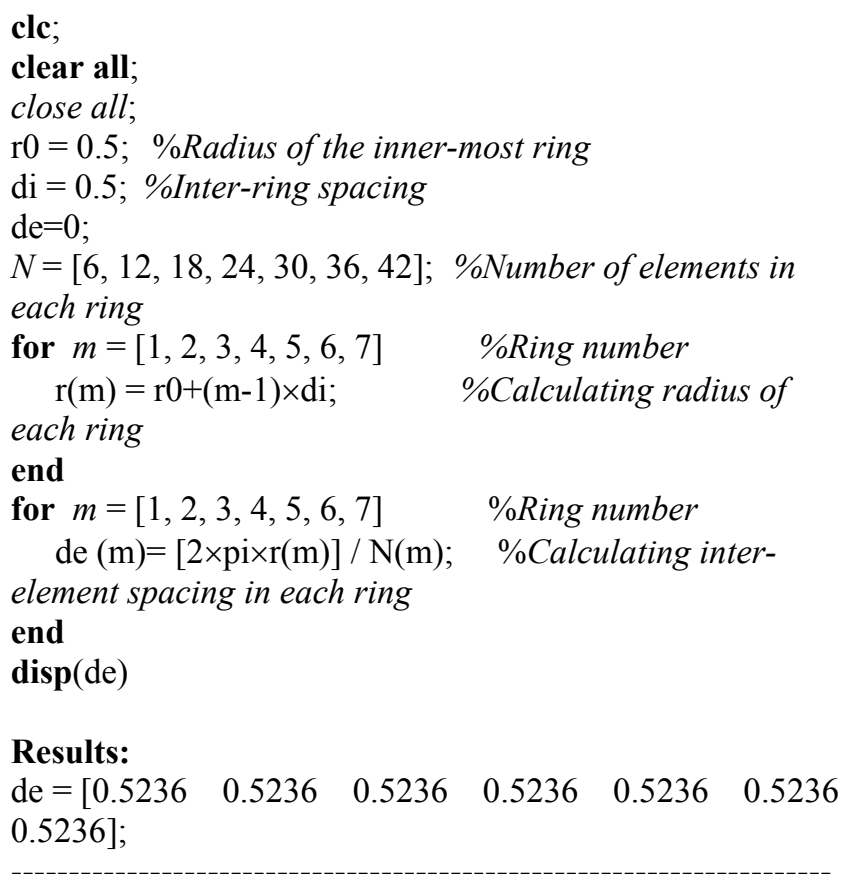

So, in our design, the inter-element spacing is $0.5236 \lambda$ for all rings in the entire array format to keep inter-ring spacing fixed at $0.5 \lambda$.

For practical applications with size limitations, the dimension of the array is the most important part of array antenna design problem. The optimized spacing between adjacent elements is so distributed that the average interelement spacing is the same as that of equally spaced array. Therefore, the total aperture area of the array is kept fixed during optimization.

Generally, inter-element spacing is to be so chosen as to ensure low-level of mutual coupling between signals received by adjacent antenna element channels. According to the theoretical results, the low mutual coupling effect is obtained for inter-element spacing more than half wave- length; however, experimental measurements show that this distance can be less [42]. Also, single wave length spacing generates grating lobes with a magnitude equal to the main lobe value. To avoid grating lobes, the spacing between the elements of the planar array is to be less than the wavelength.

\subsection{Pattern Synthesis of Thinned Concentric Circular Antenna Arrays (CCAAs)}

Thinning is the process of removing (switching OFF) antenna elements systematically from uniformly spaced array without a significant degradation in performance. In this procedure, all the elements have any of two situations; "ON" (excited) or "OFF" (detached). It is one of the best solutions to lower the side lobes of antenna arrays. Some elements within a ring of an array are turned off or removed to modify current density on the aperture. The goal is to minimize the maximum side lobe density taper on the array aperture. We apply GSA, PSO \& GSA-PSO to optimize the proposed designing problem. SLL performances of different thinned array formats using these three evolutionary techniques are shown in Tab. 2 and described below.

Array-1: Upon applying GSA for thinned CCAA of 2 rings having $(6,12)$ elements, $50 \%$ thinning is used to reduce SLL to $-16.05 \mathrm{~dB}$ with FNBW $56.8^{\circ}$ considering 9 elements as $\mathrm{ON}$ in total. Similarly, using PSO for thinned CCAA array of the same configuration, $27.78 \%$ thinning is used to reduce SLL to $-17.52 \mathrm{~dB}$ with FNBW $60.4^{\circ}$ considering 13 elements as $\mathrm{ON}$ in total. Also, using GSA-PSO, $55.56 \%$ thinning is used to reduce SLL to $-24.41 \mathrm{~dB}$ with FNBW $65^{\circ}$ considering 8 elements as $\mathrm{ON}$ in total.

Array-2: Using GSA for thinned CCAA of 3 rings having $(6,12,18)$ elements, $36.11 \%$ thinning is used to reduce SLL to $-19.68 \mathrm{~dB}$ with FNBW $43.2^{\circ}$ considering 23 elements as $\mathrm{ON}$ in total. By the use of PSO for thinned CCAA array of 3 rings having $(6,12,18)$ elements, $22.22 \%$ thinning is used to reduce SLL to $-21.80 \mathrm{~dB}$ with FNBW $46.4^{\circ}$ considering 28 elements as $\mathrm{ON}$ in total. Upon applying GSA-PSO for thinned CCAA array of 3 rings having $(6,12,18)$ elements, $36.11 \%$ thinning is used to reduce SLL to $-23.41 \mathrm{~dB}$ with FNBW $47.6^{\circ}$ considering 23 elements as $\mathrm{ON}$ in total.

Array-3: Upon applying GSA for thinned CCAA of 4 rings having $(6,12,18,24)$ elements, $48.43 \%$ thinning is used to reduce SLL to $-24.68 \mathrm{~dB}$ with FNBW $37.2^{\circ}$ considering 31 elements as $\mathrm{ON}$ in total. Upon applying PSO for thinned CCAA array of 4 rings having $(6,12,18,24)$ elements, $50 \%$ thinning is used to reduce SLL to $-26.47 \mathrm{~dB}$ with FNBW $38.8^{\circ}$ considering 30 elements as $\mathrm{ON}$ in total. Upon applying GSA-PSO for thinned CCAA array of 4 rings having $(6,12,18,24)$ elements, $43.33 \%$ thinning is used to reduce SLL to $-28.07 \mathrm{~dB}$ with FNBW $40.4^{\circ}$ considering 34 elements as $\mathrm{ON}$ in total.

Array-4: Applying GSA for thinned CCAA array of 5 rings having $(6,12,18,24,30)$ elements, $37.78 \%$ thinning is used to reduce SLL to $-21.58 \mathrm{~dB}$ with FNBW $28^{\circ}$ 
considering 56 elements as $\mathrm{ON}$ in total. Using PSO for thinned CCAA array of 5 rings having $(6,12,18,24,30)$ elements, $57.78 \%$ thinning is used to reduce SLL to $-22.42 \mathrm{~dB}$ with FNBW $27.2^{\circ}$ considering 38 elements as $\mathrm{ON}$ in total. Upon applying GSA-PSO for thinned CCAA array of 5 rings having $(6,12,18,24,30)$ elements, $42.22 \%$ thinning is used to reduce SLL to $-25.01 \mathrm{~dB}$ with FNBW $30^{\circ}$ considering 52 elements as $\mathrm{ON}$ in total.

Array-5: Upon applying GSA for thinned CCAA array of 6 rings having $(6,12,18,24,30,36)$ elements, $48.42 \%$ thinning is used to reduce SLL to $-24.92 \mathrm{~dB}$ with FNBW $26^{\circ}$ considering 65 elements as ON in total. With PSO for thinned CCAA array of 6 rings having $(6,12,18$, $24,30,36$ ) elements, $42.86 \%$ thinning is used to reduce SLL to $-26.83 \mathrm{~dB}$ with FNBW $26.8^{\circ}$ considering 72 elements as $\mathrm{ON}$ in total. Upon applying GSA-PSO for thinned CCAA array of 6 rings having $(6,12,18,24,30,36)$ elements, $42.07 \%$ thinning is used to reduce SLL to $-29.26 \mathrm{~dB}$ with FNBW $27.6^{\circ}$ considering 73 elements as $\mathrm{ON}$ in total.

Array-6: Using GSA for thinned CCAA array of 7 rings having $(6,12,18,24,30,36,42)$ elements, $45.24 \%$ thinning is used to reduce SLL to $-24.17 \mathrm{~dB}$ with FNBW $21.2^{\circ}$ considering 92 elements as $\mathrm{ON}$ in total. Upon applying PSO for thinned CCAA array of 7 rings having $(6,12$, $18,24,30,36,42$ ) elements, $50.60 \%$ thinning is used to reduce SLL to $-26.17 \mathrm{~dB}$ with FNBW $22.8^{\circ}$ considering 83 elements as ON in total. By GSA-PSO for thinned CCAA array of 7 rings having $(6,12,18,24,30,36,42)$ elements, $39.89 \%$ thinning is used to reduce SLL to $-28.21 \mathrm{~dB}$ with FNBW $23.2^{\circ}$ considering 101 elements as $\mathrm{ON}$ in total.

Figures 2(a-f) show the normalized absolute power patterns of optimized thinned CCAAs found by GSA, PSO and GSA-PSO for all array sets. It is observed that the number of antenna array elements can be brought down with the simultaneous reduction in SLL achieved after thinning; as compared to the fully populated array (uniformly excited array) with fixed inter-element spacing. Excitation amplitude distribution of optimized thinned CCAA using GSA, PSO and GSA-PSO are tabulated in Tab. 3, Tab. 4 and Tab. 5, respectively, for all CCAA formats. Filled ratio is also tabulated in respective table for each array size and for each optimization algorithm. Filled ratio is the ratio of the number of $\mathrm{ON}$ elements to the total number of elements in the array.

Findings: (i) From Fig. 2 and Tab. 2, it can be seen that CCAA of all array sets gives the lowest value of SLL using GSA-PSO $(-17.81 \mathrm{~dB}$ for Array-1, $-23.41 \mathrm{~dB}$ for Array-2, $-28.07 \mathrm{~dB}$ for Array-3, $-25.01 \mathrm{~dB}$ for Array-4, $-29.26 \mathrm{~dB}$ for Array-5, $-28.21 \mathrm{~dB}$ for Array-6) when compared with GSA and PSO techniques. (ii) Percentage of thinning (number of OFF elements in percent) is more than $40 \%$ using GSA-PSO for all array sets (Tab. 5) except Array-2 where thinning is $36.11 \%$. Higher value of array thinning gives less mutual coupling effect from the adjacent elements. Also, the cost and weight of the array is lower with higher value of thinning. (iii) Furthermore, CCAA using GSA-PSO not only gives the best SLL, radia- tion pattern using GSA-PSO gives the narrower main beam width (FNBW) among the three optimization algorithms in many cases.

\subsection{Pattern Synthesis of Non-Uniform Concen- tric Circular Antenna Arrays (CCAAs)}

In the second example, we have considered CCAA of a fixed inter-element spacing is $0.5236 \lambda$ for all rings in the entire array format to keep inter-ring spacing fixed at $0.5 \lambda$. Synthesis of CCAA is achieved by GSA, PSO and GSAPSO techniques. The ring radius of each ring in CCAA is defined by the product of the inequality constraint for the

\begin{tabular}{|c|c|c|c|c|c|c|}
\hline \multirow{2}{*}{$\begin{array}{c}\text { Array } \\
\text { set }\end{array}$} & \multicolumn{2}{|c|}{ GSA } & \multicolumn{2}{c|}{ PSO } & \multicolumn{2}{c|}{ GSA-PSO } \\
\cline { 2 - 7 } & $\begin{array}{c}\text { SLL } \\
\text { (dB) }\end{array}$ & $\begin{array}{c}\text { FNBW } \\
\text { (deg) }\end{array}$ & $\begin{array}{c}\text { SLL } \\
\text { (dB) }\end{array}$ & $\begin{array}{c}\text { FNBW } \\
\text { (deg) }\end{array}$ & $\begin{array}{c}\text { SLL } \\
\text { (dB) }\end{array}$ & $\begin{array}{c}\text { FNBW } \\
\text { (deg) }\end{array}$ \\
\hline Array-1 & -16.05 & 56.8 & -17.52 & 60.4 & -17.81 & 59.6 \\
\hline Array-2 & -19.68 & 43.2 & -21.80 & 46.4 & -23.41 & 47.6 \\
\hline Array-3 & -24.68 & 37.2 & -26.47 & 38.8 & -28.07 & 40.4 \\
\hline Array-4 & -21.58 & 28.0 & -22.42 & 27.2 & -25.01 & 30.0 \\
\hline Array-5 & -24.92 & 26.0 & -26.83 & 26.8 & -29.26 & 27.6 \\
\hline Array-6 & -24.17 & 21.2 & -26.17 & 22.8 & -28.21 & 23.2 \\
\hline
\end{tabular}

Tab. 2. Performances of different sets of thinned CCAA using three optimization techniques.

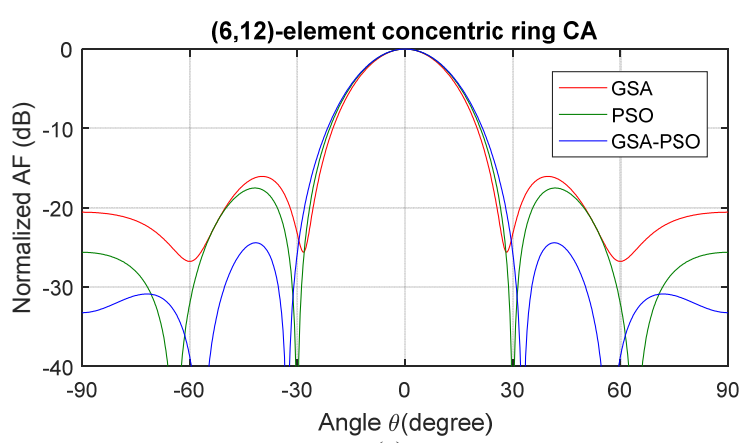

(a)

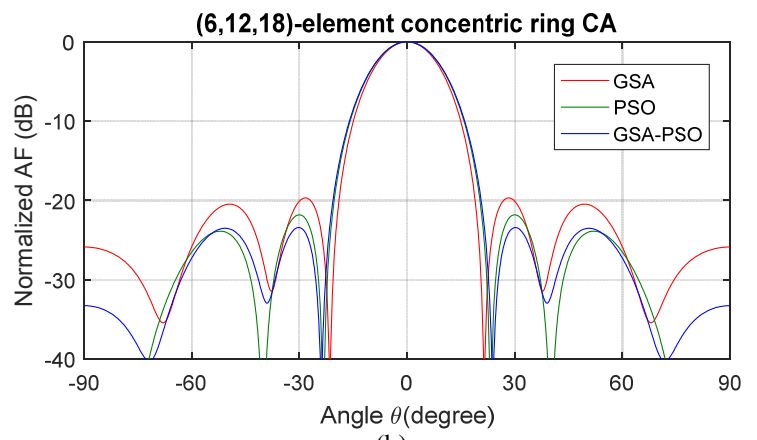

(b) 


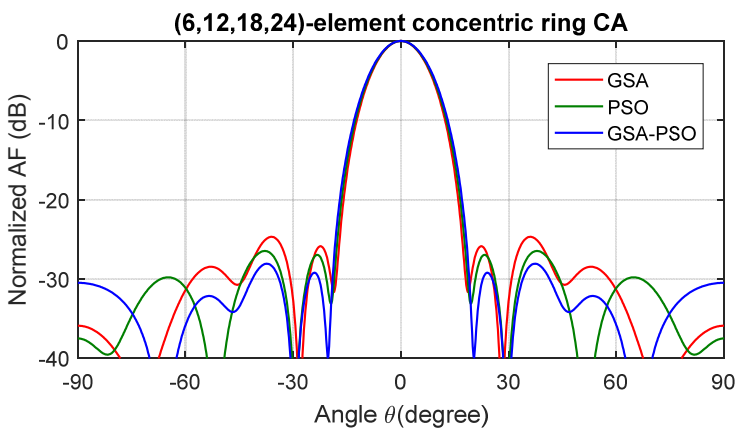

(c)

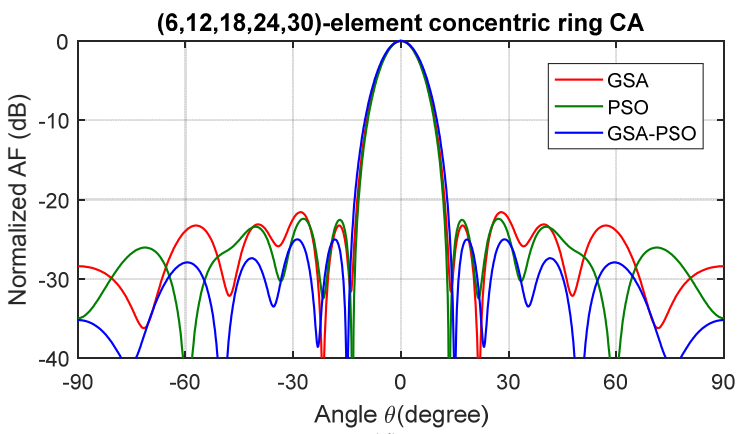

(d)

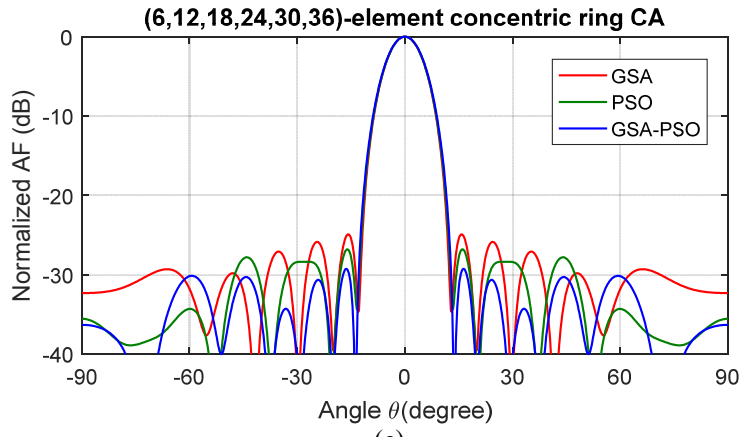

(e)

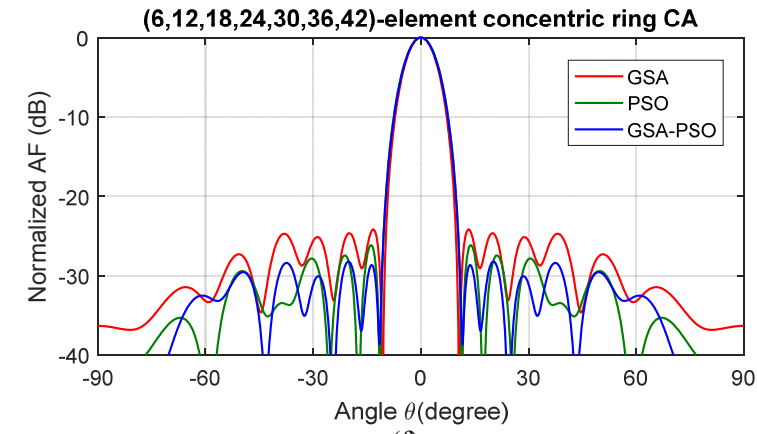

(f)

Fig. 2. Optimal power patterns of thinned CCAA 9: (a) array-1, (b) array-2, (c) array-3, (d) array-4, (e) array-5, (f) array-6.

inter-element spacing, $d(=0.5263 \lambda)$, and the number of elements in that particular ring $N_{i}$, i.e. $r_{i}=N_{i} d / 2 \pi . \phi_{0}=0^{\circ}$ is considered to maintain the main lobe starts from the origin for all the cases.

As mentioned earlier, this example involves optimal design of different sets of concentric circular antenna arrays arranged in a format like array of 2 rings having $(6,12)$ elements called array-1, array of 3 rings having $(6,12,18)$ elements called array- 2 , array of 4 rings having $(6,12,18,24)$

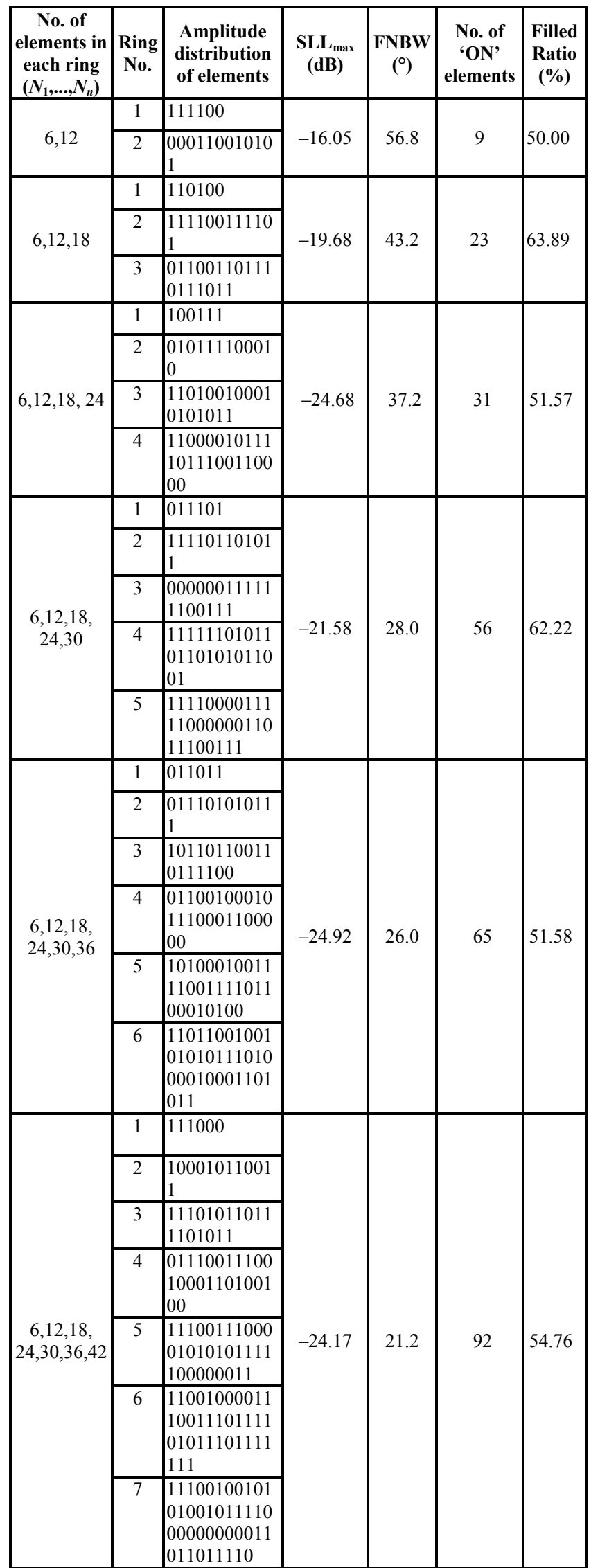

Tab. 3. Excitation amplitude distribution of optimized thinned CCAA using GSA. 


\begin{tabular}{|c|c|c|c|c|c|c|}
\hline \begin{tabular}{|c|} 
No. of \\
elements in \\
each ring \\
$\left(N_{1}, \ldots N_{n}\right)$ \\
\end{tabular} & $\begin{array}{c}\text { Ring } \\
\text { No. }\end{array}$ & $\begin{array}{l}\text { Amplitude } \\
\text { distribution } \\
\text { of elements }\end{array}$ & $\begin{array}{l}\text { SLL }_{\max } \\
\text { (dB) }\end{array}$ & $\begin{array}{c}\text { FNBW } \\
\left({ }^{\circ}\right)\end{array}$ & $\begin{array}{l}\text { No. of } \\
\text { 'ON' } \\
\text { elements }\end{array}$ & $\begin{array}{c}\text { Filled } \\
\text { ratio } \\
(\%)\end{array}$ \\
\hline \multirow[b]{2}{*}{6,12} & 1 & 111111 & \multirow[b]{2}{*}{-17.52} & \multirow[b]{2}{*}{60.4} & \multirow[b]{2}{*}{13} & \multirow[b]{2}{*}{72.22} \\
\hline & 2 & $\begin{array}{l}0011011111 \\
00\end{array}$ & & & & \\
\hline \multirow{3}{*}{$6,12,18$} & 1 & \begin{tabular}{|l|l|}
111110 \\
\end{tabular} & \multirow{3}{*}{-21.80} & \multirow{3}{*}{46.4} & \multirow{3}{*}{28} & \multirow{3}{*}{77.78} \\
\hline & 2 & $\begin{array}{l}1111101111 \\
11\end{array}$ & & & & \\
\hline & 3 & $\begin{array}{l}1100110101 \\
11111001\end{array}$ & & & & \\
\hline \multirow{4}{*}{$6,12,18,24$} & 1 & 100111 & \multirow{4}{*}{-26.47} & \multirow{4}{*}{38.8} & \multirow{4}{*}{30} & \multirow{4}{*}{50.00} \\
\hline & 2 & $\begin{array}{l}0101011010 \\
01\end{array}$ & & & & \\
\hline & 3 & $\begin{array}{l}0110101011 \\
00110101\end{array}$ & & & & \\
\hline & 4 & $\begin{array}{l}0100001001 \\
1010100110 \\
0011\end{array}$ & & & & \\
\hline \multirow{5}{*}{$\begin{array}{c}6,12,18 \\
24,30\end{array}$} & 1 & 110010 & \multirow{5}{*}{-22.42} & \multirow{5}{*}{27.2} & \multirow{5}{*}{38} & \multirow{5}{*}{42.22} \\
\hline & 2 & $\begin{array}{l}0000100011 \\
11\end{array}$ & & & & \\
\hline & 3 & \begin{tabular}{|l|}
1001000011 \\
0101000 \\
\end{tabular} & & & & \\
\hline & 4 & $\begin{array}{l}1010100110 \\
1101001100 \\
1100\end{array}$ & & & & \\
\hline & 5 & $\begin{array}{l}0000100110 \\
0011110100 \\
0011100001 \\
\end{array}$ & & & & \\
\hline \multirow{6}{*}{$\begin{array}{l}6,12,18 \\
24,30,36\end{array}$} & 1 & 011111 & \multirow{6}{*}{-26.83} & \multirow{6}{*}{26.8} & \multirow{6}{*}{72} & \multirow{6}{*}{57.14} \\
\hline & 2 & $\begin{array}{l}1101000111 \\
01\end{array}$ & & & & \\
\hline & 3 & $\begin{array}{l}1101011010 \\
01101111\end{array}$ & & & & \\
\hline & 4 & \begin{tabular}{|l|}
1011010111 \\
1110110000 \\
0101 \\
\end{tabular} & & & & \\
\hline & 5 & $\begin{array}{l}0111101001 \\
0101011100 \\
1101111101\end{array}$ & & & & \\
\hline & 6 & \begin{tabular}{|l|}
1100000010 \\
1001001110 \\
0010000111 \\
001101 \\
\end{tabular} & & & & \\
\hline \multirow{7}{*}{$\begin{array}{c}6,12,18, \\
24,30,36,42\end{array}$} & 1 & 101110 & \multirow{7}{*}{-26.17} & \multirow{7}{*}{22.8} & \multirow{7}{*}{83} & \multirow{7}{*}{49.40} \\
\hline & 2 & $\begin{array}{l}1010101010 \\
11\end{array}$ & & & & \\
\hline & 3 & $\begin{array}{l}0100100010 \\
00011010\end{array}$ & & & & \\
\hline & 4 & $\begin{array}{l}1100000110 \\
1111011110 \\
0001\end{array}$ & & & & \\
\hline & 5 & $\begin{array}{l}1011110010 \\
111011110 \\
1100100111\end{array}$ & & & & \\
\hline & 6 & $\begin{array}{l}1111000110 \\
0000011000 \\
1100010000 \\
101010 \\
\end{array}$ & & & & \\
\hline & 7 & $\begin{array}{l}0011011101 \\
0001001001 \\
1010000111 \\
0010000110 \\
11\end{array}$ & & & & \\
\hline
\end{tabular}

Tab. 4. Excitation amplitude distribution of optimized thinned CCAA using PSO.

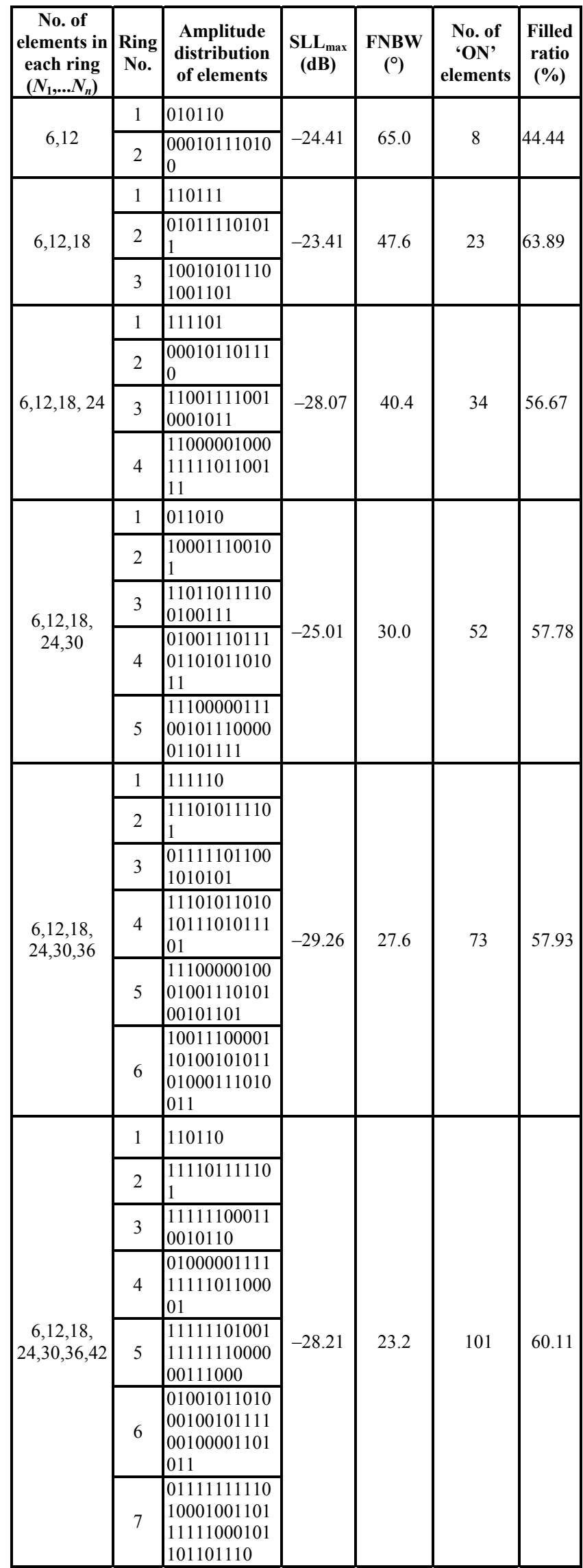

Tab. 5. Excitation amplitude distribution of optimized thinned CCAA using GSA-PSO. 
elements called array-3, array of 5 rings having $(6,12,18$, 24,30 ) elements called array-4, array of 6 rings having (6, $12,18,24,30,36)$ elements called array- 5 and array of 7 rings having $(6,12,18,24,30,36,42)$ elements called array-6, respectively, with fixed inter-ring spacing of $0.5 \lambda$. So, the number of rings in the array is chosen arbitrarily from a small size (array-1 having two rings) to a large value (array-6 having seven rings) because the total number of elements in the array have a great influence on the array pattern synthesis. FNBW/HPBW in the array pattern decreases with the increment of the total number of elements in the array. Thus, the array directivity increases with the increment in the number of elements. But, the SLL increases with the number of elements in the array. In order to reduce the SLL values, various evolutionary optimization techniques have been applied in non-uniformly distributed CCAA.

\begin{tabular}{|c|c|c|c|c|c|c|}
\hline \multirow{2}{*}{$\begin{array}{c}\text { Array } \\
\text { set }\end{array}$} & \multicolumn{2}{|c|}{ GSA } & \multicolumn{2}{|c|}{ PSO } & \multicolumn{2}{|c|}{ GSA-PSO } \\
\hline & $\begin{array}{l}\text { SLL } \\
\text { (dB) }\end{array}$ & $\begin{array}{c}\text { FNBW } \\
\text { (deg) }\end{array}$ & $\begin{array}{l}\text { SLL } \\
\text { (dB) }\end{array}$ & $\begin{array}{c}\text { FNBW } \\
\text { (deg) }\end{array}$ & $\begin{array}{l}\text { SLL } \\
\text { (dB) }\end{array}$ & $\begin{array}{c}\text { FNBW } \\
\text { (deg) }\end{array}$ \\
\hline Array-1 & -18.32 & 60.0 & -20.35 & 60.0 & -24.41 & 64.0 \\
\hline Array-2 & -29.97 & 54.0 & -33.18 & 54.4 & -34.45 & 55.2 \\
\hline Array-3 & -35.24 & 44.0 & -36.89 & 46.4 & -40.97 & 48.4 \\
\hline Array-4 & -33.14 & 36.0 & -36.29 & 36.0 & -38.11 & 37.2 \\
\hline Array-5 & -33.15 & 33.0 & -35.57 & 31.2 & -38.53 & 32.0 \\
\hline Array-6 & -30.93 & 24.4 & -33.24 & 25.6 & -37.69 & 27.6 \\
\hline
\end{tabular}

Tab. 6. Performances of different sets of non-uniform CCAA using three optimization techniques.

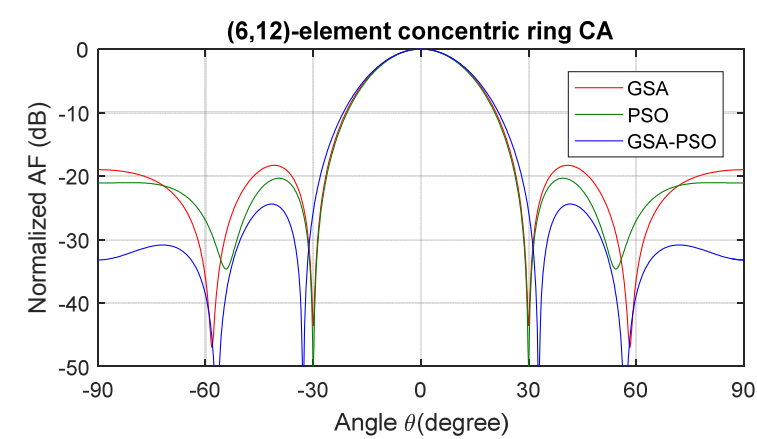

(a)

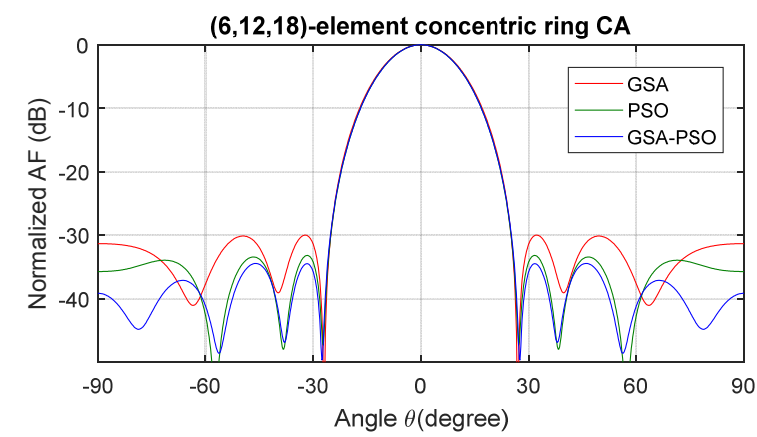

(b)

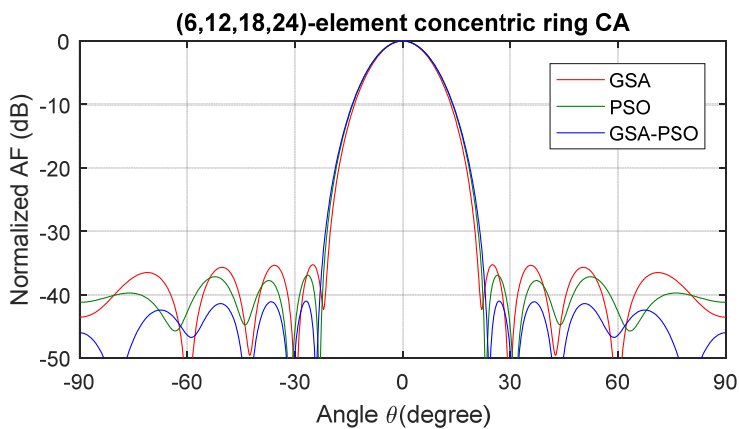

(c)

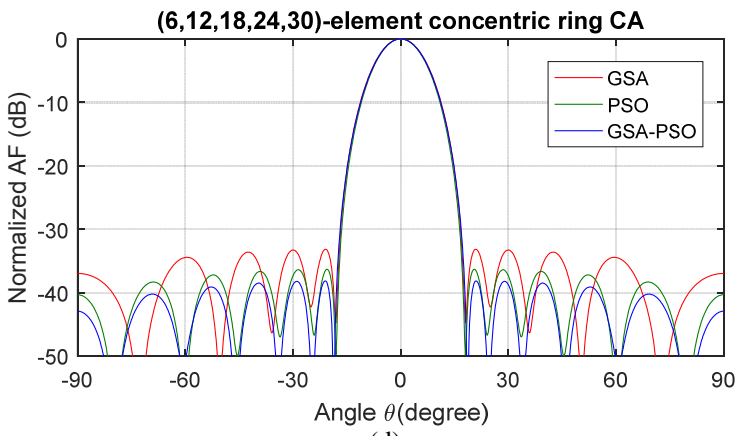

(d)

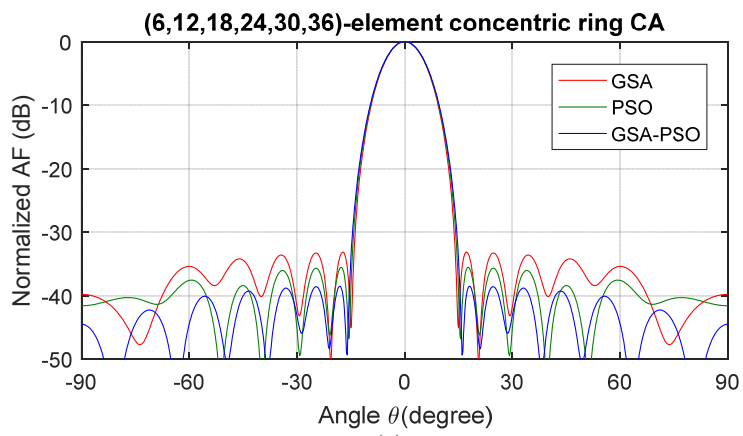

(e)

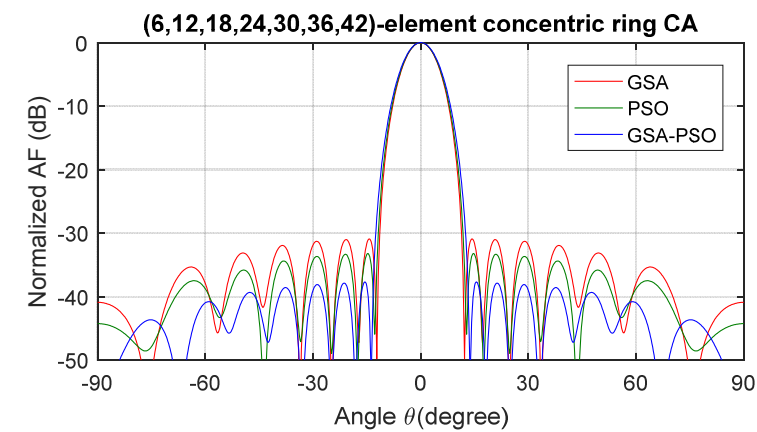

(f)

Fig. 3. Optimal power patterns of non-uniformly optimized CCAA: (a) array-1, (b) array-2, (c) array-3, (d) array-4, (e) array-5, (f) array-6.

Performances of amplitudes only for optimized CCAAs (array-1 to 6) in terms of SLL and FNBW using GSA, PSO and GSA-PSO are tabulated in Tab. 6. The nonuniformly distributed optimal excitation amplitudes for all array sets are shown in Tab. 7-9, respectively, using GSA, PSO and GSA-PSO. Figures 3(a-f) show the normalized absolute power patterns of optimized non-uniform CCAAs found by GSA, PSO and GSA-PSO for all array sets. 
Findings: (i) As shown in Tab. 6, SLL reduces to $-18.32 \mathrm{~dB}$ and $-20.35 \mathrm{~dB}$ using GSA and PSO, respectively, for array-1. Further improvement is achieved for array-1 when hybrid GSA-PSO is being applied and gives the maximum reduced SLL of $-24.41 \mathrm{~dB}$ which is the best SLL among all evolutionary schemes applied here in order to reduce the maximum SLL by optimizing the amplitude coefficients of array elements with closely equal value of FNBW. Similarly, GSA-PSO achieves maximum reduction in highest SLL as compared to the conventional GSA and PSO techniques for all the array sets with the little bit compromisation of FNBW value. (ii) From Tab. 2 and Tab. 6, it can be concluded that a lower SLL can be further achieved by optimizing the non-uniform excitation amplitude coefficients of the array rather than that of the uniform case. (ii) Narrower main lobe width can be achieved by increasing the number of rings as well as number of elements in the array as shown in Fig. 3(a-f).

\begin{tabular}{|c|c|c|c|c|c|c|}
\hline \multirow{3}{*}{\begin{tabular}{|c|c}
$\begin{array}{c}\text { No. of } \\
\text { elements in } \\
\text { each ring } \\
\left(\boldsymbol{N}_{1}, N_{2}, \ldots, N_{n}\right)\end{array}$ \\
6,12
\end{tabular}} & \multirow{3}{*}{$\begin{array}{c}\begin{array}{c}\text { Ring } \\
\text { No. }\end{array} \\
1 \\
2\end{array}$} & \multicolumn{3}{|c|}{$\begin{array}{c}\text { Amplitude distribution } \\
\text { of elements }\end{array}$} & \multirow{3}{*}{\begin{tabular}{|c}
$\begin{array}{c}\mathbf{S L L}_{\max } \\
\text { (dB) }\end{array}$ \\
-18.32
\end{tabular}} & \multirow{3}{*}{$\begin{array}{c}\begin{array}{c}\text { FNBW } \\
\left({ }^{\circ}\right)\end{array} \\
60.0\end{array}$} \\
\hline & & \multicolumn{3}{|c|}{$\left[\begin{array}{ccc}0.9931 & 0.9996 & 0 \\
0.9573 & 0.5007 & 0.3186\end{array}\right.$} & & \\
\hline & & $\begin{array}{l}0.3014 \\
1.0000 \\
1.0000 \\
1.0000\end{array}$ & $\begin{array}{c}0.6336 \\
0 \\
0.9480 \\
0.1959\end{array}$ & $\begin{array}{c}0.9604 \\
1.0000 \\
0.6419 \\
0.8307\end{array}$ & & \\
\hline \multirow[t]{3}{*}{$6,12,18$} & 1 & $\begin{array}{l}1.0000 \\
0.9759\end{array}$ & $\begin{array}{l}0.8213 \\
0.0172\end{array}$ & $\begin{array}{l}1.0000 \\
1.0000\end{array}$ & \multirow[t]{3}{*}{-29.97} & \multirow[t]{3}{*}{54.0} \\
\hline & 2 & $\begin{array}{l}1.0000 \\
0.0497 \\
0.5516 \\
0.5797\end{array}$ & $\begin{array}{l}1.0000 \\
0.6945 \\
1.0000 \\
0.6121\end{array}$ & $\begin{array}{c}0.3857 \\
1.0000 \\
1.0000 \\
1.0000\end{array}$ & & \\
\hline & 3 & $\begin{array}{l}0.9976 \\
0 \\
0.4156 \\
1.0000 \\
0 \\
1.0000\end{array}$ & $\begin{array}{r}0 \\
1.0000 \\
0.8470 \\
1.0000 \\
0 \\
0.0293\end{array}$ & $\begin{array}{l}1.0000 \\
0.0002 \\
0.5632 \\
0.7268 \\
1.0000 \\
0.5772\end{array}$ & & \\
\hline \multirow[t]{4}{*}{$6,12,18,24$} & 1 & $\begin{array}{l}0.4070 \\
0.5376\end{array}$ & $\begin{array}{r}0.7172 \\
0\end{array}$ & $\begin{array}{c}0.6306 \\
0.9769\end{array}$ & \multirow[t]{4}{*}{-35.24} & \multirow[t]{4}{*}{44.0} \\
\hline & 2 & $\begin{array}{l}0.9999 \\
0.8471 \\
1.0000 \\
0.8446\end{array}$ & $\begin{array}{l}1.0000 \\
0.1626 \\
1.0000 \\
0.6335\end{array}$ & $\begin{array}{l}0.0110 \\
1.0000 \\
0.4059 \\
0.5706\end{array}$ & & \\
\hline & 3 & $\begin{array}{l}0.8354 \\
0.7894 \\
0.1979 \\
0.3701 \\
0.9872 \\
0.4989\end{array}$ & $\begin{array}{l}0.9157 \\
0.0859 \\
0.7189 \\
1.0000 \\
0.0029 \\
0.7630\end{array}$ & $\begin{array}{r}0.6571 \\
0.7141 \\
0.2583 \\
0 \\
0.0384 \\
0.8691\end{array}$ & & \\
\hline & 4 & $\begin{array}{l}0.8211 \\
0.8152 \\
0.4391 \\
0.1866 \\
0.9102 \\
0.9958 \\
0.4838 \\
0.4086\end{array}$ & $\begin{array}{c}0.4102 \\
0.0078 \\
0 \\
0.9700 \\
0.9975 \\
0.0739 \\
0 \\
0.5661\end{array}$ & $\begin{array}{r}0.3551 \\
1.0000 \\
0.0059 \\
0.9356 \\
0 \\
0.9733 \\
0 \\
0.2377\end{array}$ & & \\
\hline
\end{tabular}

\begin{tabular}{|c|c|c|c|c|c|c|}
\hline \multirow[t]{5}{*}{$\begin{array}{l}6,12,18 \\
24,30\end{array}$} & 1 & $\begin{array}{l}0.6630 \\
0.7969\end{array}$ & $\begin{array}{l}0.7311 \\
0.9957\end{array}$ & $\begin{array}{l}0.5438 \\
0.5891\end{array}$ & \multirow[t]{5}{*}{-33.14} & \multirow[t]{5}{*}{36.0} \\
\hline & 2 & $\begin{array}{l}0.9946 \\
0.8902 \\
0.4156 \\
0.5370\end{array}$ & $\begin{array}{l}0.9989 \\
0.3686 \\
0.4655 \\
0.4628\end{array}$ & $\begin{array}{c}0.5439 \\
0.5052 \\
0.5009 \\
0.4170\end{array}$ & & \\
\hline & 3 & $\begin{array}{l}0.9952 \\
0.9904 \\
0.6607 \\
0.7905 \\
0.8211 \\
0.8144\end{array}$ & $\begin{array}{l}0.5588 \\
0.4972 \\
0.6038 \\
0.8725 \\
0.6654 \\
0.7966\end{array}$ & $\begin{array}{l}0.0633 \\
0.3558 \\
0.9042 \\
0.5964 \\
0.6387 \\
0.8295\end{array}$ & & \\
\hline & 4 & $\begin{array}{l}0.9007 \\
0.0003 \\
1.0000 \\
0.8744 \\
0.9309 \\
0.0198 \\
0.5249 \\
0.0661\end{array}$ & $\begin{array}{l}0.9988 \\
0.2186 \\
0.1090 \\
0.7615 \\
0.5851 \\
0.2205 \\
0.1632 \\
0.9497\end{array}$ & $\begin{array}{c}0.9622 \\
0.3751 \\
0.4592 \\
0.8471 \\
0.4569 \\
0.1452 \\
0.3706 \\
0.6431\end{array}$ & & \\
\hline & 5 & $\begin{array}{l}0.7079 \\
0.7697 \\
0.0015 \\
1.0000 \\
0.3044 \\
0.4824 \\
0.3824 \\
0.0016 \\
0.1700 \\
0.3634\end{array}$ & $\begin{array}{r}0.7608 \\
0.5407 \\
0.6157 \\
0 \\
0.8635 \\
0.8988 \\
0.2697 \\
0.1331 \\
0.7518 \\
0.3100\end{array}$ & $\begin{array}{r}0.6873 \\
0 \\
0.1724 \\
0.9818 \\
0.7789 \\
0.2741 \\
0.0054 \\
0.3099 \\
0.4032 \\
0.6864\end{array}$ & & \\
\hline \multirow[t]{6}{*}{$\begin{array}{l}6,12,18, \\
24,30,36\end{array}$} & 1 & $\begin{array}{l}0.9404 \\
1.0000\end{array}$ & $\begin{array}{l}0.3308 \\
0.7021\end{array}$ & $\begin{array}{l}0.2821 \\
0.8552\end{array}$ & \multirow[t]{6}{*}{-33.15} & \multirow[t]{6}{*}{33.0} \\
\hline & 2 & $\begin{array}{l}0.9737 \\
0.6620 \\
1.0000 \\
0.6835\end{array}$ & $\begin{array}{c}1.0000 \\
0.3676 \\
0.8698 \\
0.3408\end{array}$ & $\begin{array}{l}0.7515 \\
0.4997 \\
0.9148 \\
.7339\end{array}$ & & \\
\hline & 3 & $\begin{array}{l}0.9833 \\
1.0000 \\
0.7806 \\
0.9023 \\
0.8012 \\
1.0000\end{array}$ & $\begin{array}{r}1.0000 \\
0 \\
0 \\
1.0000 \\
0.3153 \\
0.8730\end{array}$ & $\begin{array}{r}0.9002 \\
1.0000 \\
0.6262 \\
0 \\
1.0000 \\
1.0000\end{array}$ & & \\
\hline & 4 & $\begin{array}{l}1.0000 \\
1.0000 \\
0.9790 \\
0.7250 \\
0 \\
0.1519 \\
0.5166 \\
1.0000\end{array}$ & $\begin{array}{r}0.9941 \\
0.926 \\
0 \\
0.8969 \\
0.9892 \\
0.5450 \\
0.2648 \\
1.0000\end{array}$ & $\begin{array}{r}0.3034 \\
0 \\
1.0000 \\
0.7790 \\
1.0000 \\
0 \\
0.8318 \\
0.9865\end{array}$ & & \\
\hline & 5 & \begin{tabular}{|l}
1.0000 \\
0.6212 \\
0.6529 \\
0 \\
0.0101 \\
0.1202 \\
0 \\
0 \\
0.0012 \\
0.9843
\end{tabular} & $\begin{array}{c}0.9744 \\
0.4449 \\
0.2131 \\
1.0000 \\
0.3905 \\
0.1065 \\
1.0000 \\
0.6219 \\
0.5832 \\
0.7688\end{array}$ & $\begin{array}{r}0.6781 \\
0.3468 \\
0.0306 \\
0 \\
0.3771 \\
1.0000 \\
0.0120 \\
1.0000 \\
0.4007 \\
0.8135\end{array}$ & & \\
\hline & 6 & $\begin{array}{l}0.3335 \\
0.0657 \\
0.5226 \\
0.0305 \\
0 \\
0.0271\end{array}$ & $\begin{array}{l}0.9867 \\
0.1625 \\
0.3423 \\
0.3116 \\
0.3511 \\
0.3780\end{array}$ & $\begin{array}{l}1.0000 \\
0.3020 \\
0.6899 \\
0.0037 \\
0.3960 \\
0.8280\end{array}$ & & \\
\hline
\end{tabular}




\begin{tabular}{|c|c|c|c|c|c|c|}
\hline & & $\begin{array}{l}1.0000 \\
0.0797 \\
1.0000 \\
0.8418 \\
0 \\
0.6758\end{array}$ & $\begin{array}{r}0.8995 \\
0.2699 \\
0 \\
0.0335 \\
0.7211 \\
0.1967\end{array}$ & $\begin{array}{r}0.5052 \\
0.4637 \\
0.6268 \\
0 \\
0.9198 \\
0.0382\end{array}$ & & \\
\hline \multirow[t]{7}{*}{$\begin{array}{l}6,12,18, \\
24,30,36,42\end{array}$} & 1 & $\begin{array}{l}0.1503 \\
0.8407\end{array}$ & $\begin{array}{l}0.8867 \\
0.9354\end{array}$ & $\begin{array}{c}0.4714 \\
0.0438\end{array}$ & \multirow[t]{7}{*}{-30.93} & \multirow[t]{7}{*}{24.4} \\
\hline & 2 & $\begin{array}{l}0.9995 \\
0.4600 \\
0.6036 \\
0.9706\end{array}$ & $\begin{array}{l}0.2817 \\
1.0000 \\
0.5191 \\
0.4944\end{array}$ & $\begin{array}{l}0.3293 \\
1.0000 \\
0.7071 \\
0.9668\end{array}$ & & \\
\hline & 3 & $\begin{array}{l}0.5421 \\
0.6942 \\
0.8012 \\
0.5869 \\
0.4565 \\
0.9989\end{array}$ & $\begin{array}{l}0.6076 \\
1.0000 \\
0.3586 \\
0.4459 \\
0.8824 \\
0.7373\end{array}$ & $\begin{array}{c}0.7004 \\
0.9950 \\
0.5277 \\
0.5224 \\
0.4206 \\
1.0000\end{array}$ & & \\
\hline & 4 & $\begin{array}{l}0.9792 \\
0.4139 \\
0.3962 \\
0 \\
0.3252 \\
0.1823 \\
0.6044 \\
0.6689\end{array}$ & $\begin{array}{l}0.8685 \\
0.2713 \\
0.8440 \\
0.0856 \\
0.2925 \\
0.9452 \\
0.3850 \\
0.9997\end{array}$ & $\begin{array}{r}0.5058 \\
0.5260 \\
0.6760 \\
0.9940 \\
0.8697 \\
0.2980 \\
0.6249 \\
0.5322\end{array}$ & & \\
\hline & 5 & $\begin{array}{l}0.7309 \\
0.4939 \\
1.0000 \\
0.8967 \\
0.1868 \\
0.9107 \\
0.4869 \\
0.7729 \\
0.5723 \\
0.6036\end{array}$ & $\begin{array}{l}0.5849 \\
0.2778 \\
0.8533 \\
0.5071 \\
0.8921 \\
0.8067 \\
0.6194 \\
0.2676 \\
0.8021 \\
0.2101\end{array}$ & $\begin{array}{r}0.4330 \\
0.1322 \\
0 \\
0.9204 \\
0.3480 \\
0.4163 \\
0.0005 \\
0.9992 \\
0.1593 \\
0.1080\end{array}$ & & \\
\hline & 6 & $\begin{array}{l}0.5295 \\
0.4093 \\
0 \\
0.3097 \\
0.1846 \\
0 \\
0.4260 \\
0.4014 \\
0.2473 \\
0.0867 \\
0.0929 \\
0.2010\end{array}$ & $\begin{array}{c}0.2862 \\
0.5386 \\
0.3396 \\
0.7137 \\
0.2447 \\
0.8574 \\
1.0000 \\
0.0910 \\
0.5659 \\
0.4256 \\
0.0185 \\
0.0326\end{array}$ & $\begin{array}{r}0.3463 \\
0.1670 \\
0.3865 \\
0 \\
0.8549 \\
0.4317 \\
0.6654 \\
0.9596 \\
0.5832 \\
0.5703 \\
1.0000 \\
0.7379\end{array}$ & & \\
\hline & 7 & $\begin{array}{l}1.0000 \\
0.6329 \\
0.2877 \\
0.0419 \\
0.8027 \\
0.9303 \\
0.9020 \\
0.8765 \\
0.8009 \\
0.0000 \\
0.0034 \\
0.3933 \\
0.0428 \\
0.1018\end{array}$ & $\begin{array}{c}0.8853 \\
0.1474 \\
0 \\
0.1595 \\
0.6492 \\
0.2415 \\
0.9021 \\
1.0000 \\
0.4649 \\
0.0159 \\
0.9992 \\
0.5479 \\
0 \\
0.1658\end{array}$ & $\begin{array}{r}0.8195 \\
0.2294 \\
0.2215 \\
0.2739 \\
0.2724 \\
0.0296 \\
0.8160 \\
0.9438 \\
0.0000 \\
0 \\
0 \\
0.6373 \\
0.0263 \\
.2956\end{array}$ & & \\
\hline
\end{tabular}

Tab. 7. Excitation amplitude distribution of optimized nonuniform CCAA using GSA.

\begin{tabular}{|c|c|c|c|c|c|c|}
\hline \multirow{3}{*}{\begin{tabular}{|l}
$\begin{array}{c}\text { No. of } \\
\text { elements in } \\
\text { each ring } \\
\left(N_{1}, N_{2}, \ldots, N_{n}\right)\end{array}$ \\
6,12
\end{tabular}} & \multirow{2}{*}{$\begin{array}{c}\begin{array}{c}\text { Ring } \\
\text { No. }\end{array} \\
1\end{array}$} & \multicolumn{3}{|c|}{$\begin{array}{c}\text { Amplitude distribution } \\
\text { of elements }\end{array}$} & \multirow{3}{*}{\begin{tabular}{|c}
$\begin{array}{c}\mathbf{S L L}_{\max } \\
\text { (dB) }\end{array}$ \\
-20.35
\end{tabular}} & \multirow{3}{*}{\begin{tabular}{|c}
$\begin{array}{c}\text { FNBW } \\
\left.\mathbf{(}^{\circ}\right)\end{array}$ \\
60.0
\end{tabular}} \\
\hline & & $\begin{array}{l}0 \\
0.0022\end{array}$ & $\begin{array}{l}1.0000 \\
0.2830\end{array}$ & $\begin{array}{c}0.0236 \\
1.0000\end{array}$ & & \\
\hline & 2 & $\begin{array}{l}1.0000 \\
1.0000 \\
0.9315 \\
1.0000\end{array}$ & $\begin{array}{l}0.8670 \\
0.1350 \\
0.5557 \\
0.3286\end{array}$ & $\begin{array}{r}0.0001 \\
0 \\
0 \\
0\end{array}$ & & \\
\hline \multirow[t]{3}{*}{$6,12,18$} & 1 & $\begin{array}{l}0.6162 \\
0.6577\end{array}$ & $\begin{array}{l}0.0974 \\
0.6409\end{array}$ & $\begin{array}{l}0.5834 \\
0.5290\end{array}$ & \multirow[t]{3}{*}{-33.18} & \multirow[t]{3}{*}{54.4} \\
\hline & 2 & $\begin{array}{l}0.9374 \\
0 \\
0.6413 \\
0.1952\end{array}$ & $\begin{array}{l}0.4093 \\
0.9651 \\
0.2495 \\
0.2561\end{array}$ & $\begin{array}{l}0.5194 \\
0.2364 \\
0.7178 \\
0.6327\end{array}$ & & \\
\hline & 3 & $\begin{array}{l}1.0000 \\
0 \\
0.2521 \\
0.4567 \\
0 \\
0\end{array}$ & $\begin{array}{l}0.7450 \\
0.0107 \\
0.2256 \\
0.4628 \\
0.3333 \\
0.7771\end{array}$ & \begin{tabular}{r|}
0.5398 \\
1.0000 \\
1.0000 \\
0.6476 \\
0.8724 \\
0.7117
\end{tabular} & & \\
\hline \multirow[t]{4}{*}{$6,12,18,24$} & 1 & $\begin{array}{l}0.5325 \\
0.4202\end{array}$ & $\begin{array}{l}0.5815 \\
0.5197\end{array}$ & $\begin{array}{c}0.6867 \\
.6298\end{array}$ & \multirow[t]{4}{*}{-36.89} & \multirow[t]{4}{*}{46.4} \\
\hline & 2 & $\begin{array}{l}0.5244 \\
0.5997 \\
0.6389 \\
0.4879\end{array}$ & $\begin{array}{l}1.0000 \\
0.5929 \\
1.0000 \\
0.7346\end{array}$ & $\begin{array}{c}0.1060 \\
0.9067 \\
0.0235 \\
0.6416\end{array}$ & & \\
\hline & 3 & $\begin{array}{l}0.8022 \\
0.1716 \\
0.0355 \\
1.0000 \\
0.5995 \\
0.0422\end{array}$ & $\begin{array}{l}0.0881 \\
0.9773 \\
0.9023 \\
0.2267 \\
0.2948 \\
0.6103\end{array}$ & $\begin{array}{r}0.6217 \\
0 \\
0.7343 \\
0.4623 \\
0.5228 \\
0.9507\end{array}$ & & \\
\hline & 4 & $\begin{array}{l}0.9995 \\
0.9986 \\
0.5784 \\
0.2859 \\
0.6753 \\
0.1463 \\
0.1487 \\
0.6351\end{array}$ & $\begin{array}{r}0.6809 \\
0 \\
0 \\
0.9101 \\
0.6990 \\
0 \\
0.6592 \\
0.4651\end{array}$ & $\begin{array}{r}0 \\
0.5571 \\
0.0528 \\
0.5098 \\
0.5282 \\
0.0952 \\
0.0027 \\
0.3288\end{array}$ & & \\
\hline \multirow[t]{5}{*}{$\begin{array}{l}6,12,18 \\
24,30\end{array}$} & 1 & $\begin{array}{l}1.0000 \\
0.9250\end{array}$ & $\begin{array}{l}0.9878 \\
0.8839\end{array}$ & $\begin{array}{l}0.0618 \\
0.5132\end{array}$ & \multirow[t]{5}{*}{-36.29} & \multirow[t]{5}{*}{36.0} \\
\hline & 2 & $\begin{array}{l}0.6257 \\
0.0227 \\
0.8713 \\
0.3452\end{array}$ & $\begin{array}{l}0.6706 \\
0.9828 \\
0.5800 \\
0.5442\end{array}$ & $\begin{array}{l}0.1450 \\
0.9424 \\
0.4294 \\
0.9012\end{array}$ & & \\
\hline & 3 & $\begin{array}{l}0.7319 \\
0.4787 \\
0.1921 \\
1.0000 \\
0.8120 \\
0.4680\end{array}$ & $\begin{array}{l}0.9137 \\
0.0203 \\
0.4457 \\
0.9749 \\
0.3140 \\
0.9571\end{array}$ & $\begin{array}{l}0.4988 \\
0.6712 \\
0.4799 \\
0.3868 \\
0.3181 \\
0.1569\end{array}$ & & \\
\hline & 4 & $\begin{array}{l}0.5625 \\
0.6787 \\
0.0041 \\
0.1205 \\
0.3816 \\
0.0002 \\
0 \\
0.4982\end{array}$ & $\begin{array}{l}0.1927 \\
0.5762 \\
0.2721 \\
1.0000 \\
0.8258 \\
0.7528 \\
0.6066 \\
1.0000\end{array}$ & $\begin{array}{l}0.8606 \\
0.5459 \\
0.3311 \\
0.2435 \\
0.6901 \\
0.1365 \\
1.0000 \\
0.9969\end{array}$ & & \\
\hline & 5 & 0.7357 & 0.9136 & 0.6744 & & \\
\hline
\end{tabular}




\begin{tabular}{|c|c|c|c|c|c|c|}
\hline & & $\begin{array}{l}0.5727 \\
0.1127 \\
0.0081 \\
0.3842 \\
0.8547 \\
0.3697 \\
0.2818 \\
0.0507 \\
0.3966\end{array}$ & $\begin{array}{l}0.6660 \\
1.0000 \\
0.0020 \\
0.9964 \\
0.7074 \\
0.9237 \\
0.9817 \\
0.1248 \\
0.5256\end{array}$ & $\begin{array}{r}0.0020 \\
0.3841 \\
0.5812 \\
0.9813 \\
0.9847 \\
0 \\
0.4337 \\
0.2702 \\
0.1595\end{array}$ & & \\
\hline \multirow[t]{6}{*}{$\begin{array}{l}6,12,18, \\
24,30,36\end{array}$} & 1 & $\begin{array}{l}0.4296 \\
0.8372\end{array}$ & $\begin{array}{l}1.0000 \\
0.9898\end{array}$ & $\begin{array}{r}1.0000 \\
0.2404\end{array}$ & \multirow[t]{6}{*}{-35.57} & \multirow[t]{6}{*}{31.2} \\
\hline & 2 & {$\left[\begin{array}{l}0.4716 \\
0.5700 \\
0.0004 \\
0.1039\end{array}\right.$} & $\begin{array}{l}0.6148 \\
0.8262 \\
0.9504 \\
0.9793\end{array}$ & $\begin{array}{l}0.4300 \\
0.2249 \\
0.8610 \\
0.9893\end{array}$ & & \\
\hline & 3 & $\begin{array}{l}0.8732 \\
0.3285 \\
0.3877 \\
0.9995 \\
0.7642 \\
0\end{array}$ & $\begin{array}{c}0.7466 \\
1.0000 \\
0.3527 \\
0.9371 \\
0.5177 \\
0.8436\end{array}$ & $\begin{array}{c}1.0000 \\
0.5580 \\
0.8967 \\
0.9904 \\
0.6041 \\
0.0061\end{array}$ & & \\
\hline & 4 & $\begin{array}{l}1.0000 \\
0.3939 \\
0.4359 \\
0.5389 \\
0.4824 \\
0.8607 \\
0.5697 \\
0.9325\end{array}$ & $\begin{array}{l}0.6535 \\
0.0997 \\
0.3600 \\
0.3656 \\
1.0000 \\
0.2198 \\
0.5261 \\
0.8177\end{array}$ & $\begin{array}{l}0.7767 \\
0.4671 \\
0.0169 \\
0.3282 \\
0.2769 \\
0.1867 \\
0.9566 \\
0.6656\end{array}$ & & \\
\hline & 5 & $\begin{array}{l}1.0000 \\
0.8795 \\
0.9250 \\
0.3855 \\
0.5807 \\
1.0000 \\
0.0101 \\
0.2512 \\
0.0173 \\
0.6820\end{array}$ & $\begin{array}{l}1.0000 \\
0.7304 \\
0.0443 \\
0.3869 \\
0.9983 \\
0.9493 \\
0.1804 \\
0.2980 \\
0.9797 \\
0.7016\end{array}$ & $\begin{array}{r}0.9522 \\
0.7112 \\
0.0031 \\
0.6018 \\
0.1745 \\
0.4977 \\
0.8305 \\
0 \\
0 \\
0.1480\end{array}$ & & \\
\hline & 6 & $\begin{array}{l}0.8936 \\
1.0000 \\
0.8355 \\
0.0018 \\
0.1292 \\
0.1167 \\
0.7785 \\
1.0000 \\
0.2764 \\
1.0000 \\
0.4298 \\
0.1343\end{array}$ & $\begin{array}{r}1.0000 \\
0.0324 \\
0.0191 \\
0.8402 \\
0.2397 \\
0.7512 \\
0.1357 \\
0 \\
0.3971 \\
0 \\
0.3578 \\
0.2373\end{array}$ & $\begin{array}{r}0.0264 \\
0.0054 \\
0.3412 \\
0.0033 \\
0.6875 \\
0.6879 \\
0.2904 \\
0.0358 \\
0 \\
0 \\
0.3404 \\
0.9980\end{array}$ & & \\
\hline \multirow[t]{4}{*}{$\begin{array}{l}6,12,18, \\
24,30,36,42\end{array}$} & 1 & $\begin{array}{l}0.9893 \\
0.5815\end{array}$ & $\begin{array}{l}0.3379 \\
0.7400\end{array}$ & $\begin{array}{l}0.9995 \\
0.4282\end{array}$ & \multirow[t]{4}{*}{-33.24} & \multirow[t]{4}{*}{25.6} \\
\hline & 2 & $\begin{array}{l}0.3025 \\
0.5156 \\
0.3545 \\
0.0453\end{array}$ & $\begin{array}{l}0.4598 \\
0.2172 \\
0.9965 \\
0.9866\end{array}$ & $\begin{array}{l}0.2327 \\
0.9998 \\
0.4451 \\
0.9997\end{array}$ & & \\
\hline & 3 & $\begin{array}{l}0.0000 \\
0.7320 \\
0.5387 \\
0.9296 \\
0.3019 \\
0.9978\end{array}$ & $\begin{array}{r}0.7159 \\
0 \\
0.4194 \\
0.9799 \\
0.1334 \\
0.7779\end{array}$ & $\begin{array}{r}0.2617 \\
0.0070 \\
0.3164 \\
0.9946 \\
0.8959 \\
0.0530\end{array}$ & & \\
\hline & 4 & $\begin{array}{l}0.6208 \\
0.4226 \\
0.3140 \\
0.3469 \\
\end{array}$ & $\begin{array}{l}0.7630 \\
0.0000 \\
0.8099 \\
0.9273 \\
\end{array}$ & $\begin{array}{r}0.4027 \\
0 \\
0.5928 \\
0.4524\end{array}$ & & \\
\hline
\end{tabular}

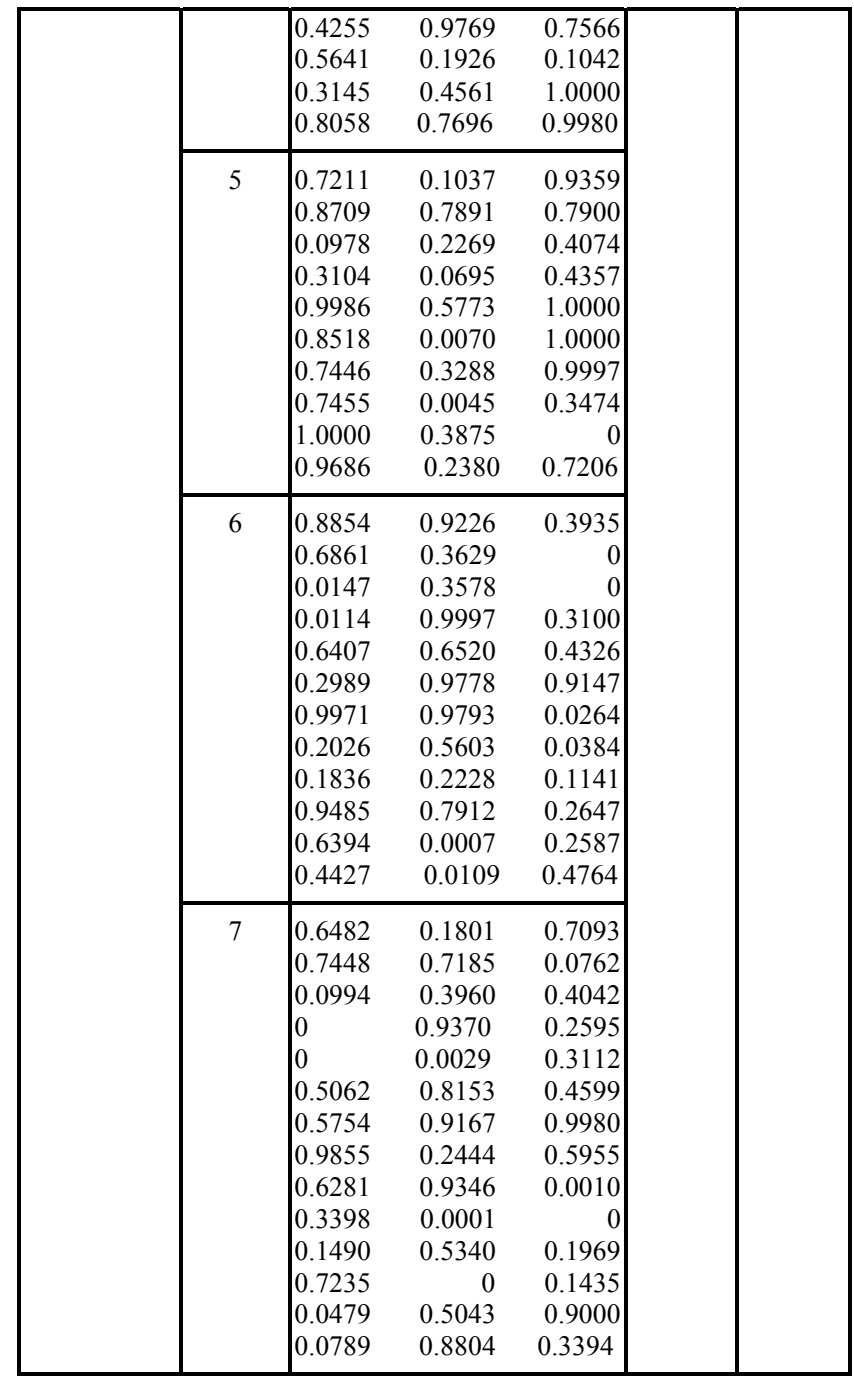

Tab. 8. Excitation amplitude distribution of optimized nonuniform CCAA using GSA.

\begin{tabular}{|c|c|c|c|c|c|c|}
\hline $\begin{array}{c}\text { No. of } \\
\text { elements in } \\
\text { each ring } \\
\left(N_{1}, N_{2}, \ldots, N_{n}\right)\end{array}$ & $\begin{array}{l}\text { Ring } \\
\text { No. }\end{array}$ & \multicolumn{3}{|c|}{$\begin{array}{l}\text { Amplitude distribution } \\
\text { of elements }\end{array}$} & $\begin{array}{l}\text { SLL } \\
\text { (dB) }\end{array}$ & $\begin{array}{c}\text { FNBW } \\
\left({ }^{\circ}\right)\end{array}$ \\
\hline \multirow[t]{2}{*}{6,12} & 1 & $\begin{array}{l}0.7763 \\
0.5641\end{array}$ & $\begin{array}{l}0.5675 \\
1.0000\end{array}$ & $\begin{array}{c}0.7282 \\
0.5268\end{array}$ & \multirow[t]{2}{*}{-24.41} & \multirow[t]{2}{*}{61.0} \\
\hline & 2 & $\begin{array}{l}1.0000 \\
1.0000 \\
0.9675 \\
0.8854\end{array}$ & $\begin{array}{c}1.0000 \\
0.4685 \\
0.7907 \\
0.2759\end{array}$ & $\begin{array}{c}0.5819 \\
0.4971 \\
0.8216 \\
0.4497\end{array}$ & & \\
\hline \multirow[t]{3}{*}{$6,12,18$} & 1 & $\begin{array}{l}0.8781 \\
1.0000\end{array}$ & $\begin{array}{c}0.5659 \\
0.6705\end{array}$ & $\begin{array}{r}0.8119 \\
0.3210\end{array}$ & \multirow[t]{3}{*}{-34.45} & \multirow[t]{3}{*}{55.2} \\
\hline & 2 & $\begin{array}{l}0.4010 \\
0.2099 \\
0.3395 \\
0.1411\end{array}$ & $\begin{array}{r}0.1093 \\
1.0000 \\
0 \\
1.0000\end{array}$ & $\begin{array}{c}0.5307 \\
0.6965 \\
0.4682 \\
1.0000\end{array}$ & & \\
\hline & 3 & $\begin{array}{l}0.4923 \\
0 \\
0 \\
0.6429 \\
0.0019 \\
0\end{array}$ & $\begin{array}{l}0 \\
0.2820 \\
0.4386 \\
0.3658 \\
1.0000 \\
0\end{array}$ & $\begin{array}{r}0.2059 \\
0.7827 \\
0.4556 \\
0.5807 \\
0.0537 \\
0.2811\end{array}$ & & \\
\hline $6,12,18,24$ & 1 & 0.8137 & 0.7051 & 1.0000 & -40.97 & 48.4 \\
\hline
\end{tabular}




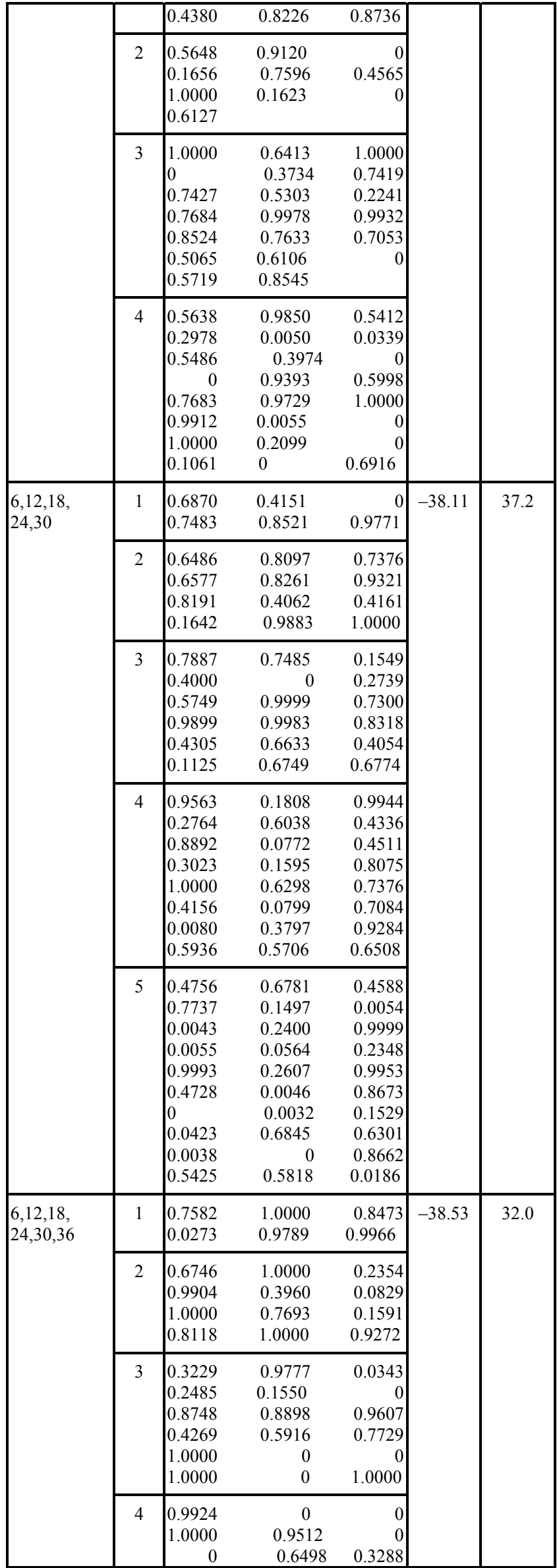

\begin{tabular}{|c|c|c|c|c|c|c|}
\hline & & $\begin{array}{l}0.7521 \\
0.7921 \\
1.0000 \\
0.4821 \\
0.4419\end{array}$ & $\begin{array}{r}0.5724 \\
1.0000 \\
0.4363 \\
0 \\
0.0353\end{array}$ & \begin{tabular}{r|}
0 \\
0 \\
0.7191 \\
0.8250 \\
0.0429
\end{tabular} & & \\
\hline & 5 & $\begin{array}{l}0.9706 \\
0.7091 \\
0.0487 \\
0 \\
0.6706 \\
0.3202 \\
0.4139 \\
0.4334 \\
0.7373 \\
0.4433\end{array}$ & $\begin{array}{c}0.5560 \\
0.5284 \\
0.0113 \\
0.2442 \\
0.9473 \\
0.9304 \\
0.2637 \\
0.5499 \\
0.8220 \\
0.6156\end{array}$ & $\begin{array}{r}0.5379 \\
0 \\
0.1710 \\
0 \\
1.0000 \\
0.9993 \\
0.2108 \\
0.5365 \\
0.0167 \\
0.1811\end{array}$ & & \\
\hline & 6 & $\begin{array}{l}1.0000 \\
0 \\
0 \\
0.3235 \\
0.1327 \\
0.0945 \\
0.5287 \\
0.9976 \\
0 \\
0.4383 \\
0 \\
0.1804\end{array}$ & $\begin{array}{r}0.6160 \\
0.7256 \\
0 \\
0 \\
1.0000 \\
0.4834 \\
0.3102 \\
0.7098 \\
0 \\
0.2687 \\
0 \\
1.0000\end{array}$ & $\begin{array}{r}0.6227 \\
1.0000 \\
0.7815 \\
0.0910 \\
0.0002 \\
0.9999 \\
0.7279 \\
0.0014 \\
0.8194 \\
0 \\
0.4770 \\
0.6895\end{array}$ & & \\
\hline \multirow[t]{6}{*}{$\begin{array}{l}6,12,18, \\
24,30,36,42\end{array}$} & 1 & $\begin{array}{l}0.9618 \\
0.6925\end{array}$ & $\begin{array}{l}0.9993 \\
0.0005\end{array}$ & $\begin{array}{l}1.0000 \\
1.0000\end{array}$ & \multirow[t]{6}{*}{-37.69} & \multirow[t]{6}{*}{27.6} \\
\hline & 2 & $\begin{array}{l}0.5743 \\
0.9867 \\
1.0000 \\
0.2880\end{array}$ & $\begin{array}{l}0.9016 \\
0.4372 \\
1.0000 \\
0.4594\end{array}$ & $\begin{array}{c}0.7556 \\
0.0477 \\
0.7243 \\
0.9609\end{array}$ & & \\
\hline & 3 & $\begin{array}{l}0.4653 \\
0.0166 \\
0.6097 \\
0.9907 \\
0.4522 \\
0.4291\end{array}$ & $\begin{array}{c}0.9999 \\
0.0286 \\
1.0000 \\
0.6382 \\
0.4728 \\
0.7965\end{array}$ & $\begin{array}{r}0.0379 \\
0 \\
0.3020 \\
0.7076 \\
0.0624 \\
1.0000\end{array}$ & & \\
\hline & 4 & $\begin{array}{l}0.9916 \\
1.0000 \\
0.1826 \\
1.0000 \\
0.6345 \\
1.0000 \\
0.3087 \\
0.0077\end{array}$ & $\begin{array}{r}1.0000 \\
0.8360 \\
0.0159 \\
0.6208 \\
0.6270 \\
0.1207 \\
0 \\
1.0000\end{array}$ & $\begin{array}{r}1.0000 \\
0.9642 \\
1.0000 \\
0.3295 \\
0 \\
0.8675 \\
0.9999 \\
0.8181\end{array}$ & & \\
\hline & 5 & $\begin{array}{l}1.0000 \\
1.0000 \\
0 \\
0.2844 \\
1.0000 \\
0.5787 \\
0.3208 \\
0 \\
0.3080 \\
0.9980\end{array}$ & $\begin{array}{l}1.0000 \\
0.4004 \\
0.8032 \\
0.1480 \\
1.0000 \\
0.3009 \\
0.8929 \\
0.4456 \\
0.5038 \\
0.9859\end{array}$ & $\begin{array}{l}0.0365 \\
0.4117 \\
0.0326 \\
0.1009 \\
0.6366 \\
1.0000 \\
0.8100 \\
0.3830 \\
0.1027 \\
0.2660\end{array}$ & & \\
\hline & 6 & $\begin{array}{l}1.0000 \\
0.9690 \\
1.0000 \\
0 \\
1.0000 \\
0.0001 \\
0.4553 \\
0.0237 \\
0.3849 \\
0.0050 \\
1.0000\end{array}$ & $\begin{array}{r}0.4455 \\
0.3785 \\
0.5017 \\
0 \\
0.9222 \\
0.2326 \\
0.5815 \\
1.0000 \\
0.1854 \\
1.0000 \\
0\end{array}$ & $\begin{array}{r}1.0000 \\
0.0376 \\
0.4899 \\
0.0774 \\
0.3926 \\
0 \\
0.1223 \\
0.0000 \\
0 \\
0.0035 \\
0.5739\end{array}$ & & \\
\hline
\end{tabular}




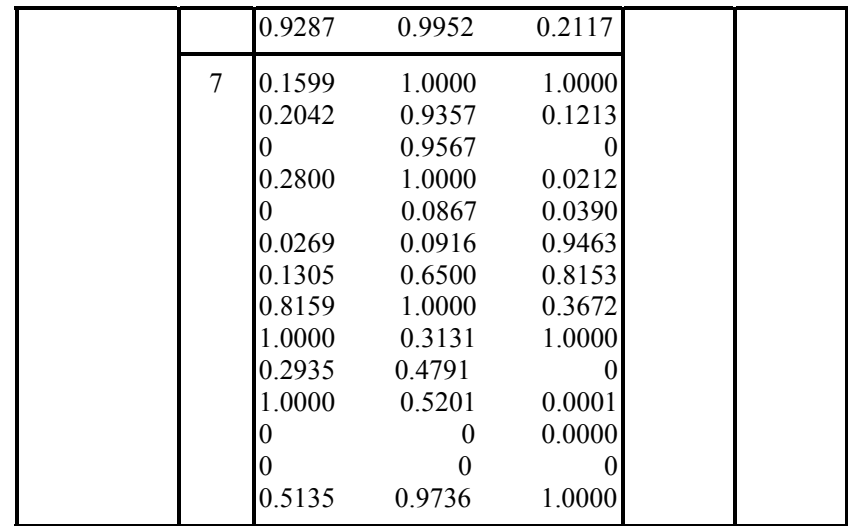

Tab. 9. Excitation amplitude distribution of optimized nonuniform CCAA using GSA-PSO.

The convergence characteristics of GSA, PSO and GSA-PSO are shown in Fig. 4 in terms of best fitness value (the minimum $C F$ value) versus iteration cycle of each algorithm. All computations were done in MATLAB 7.5 on

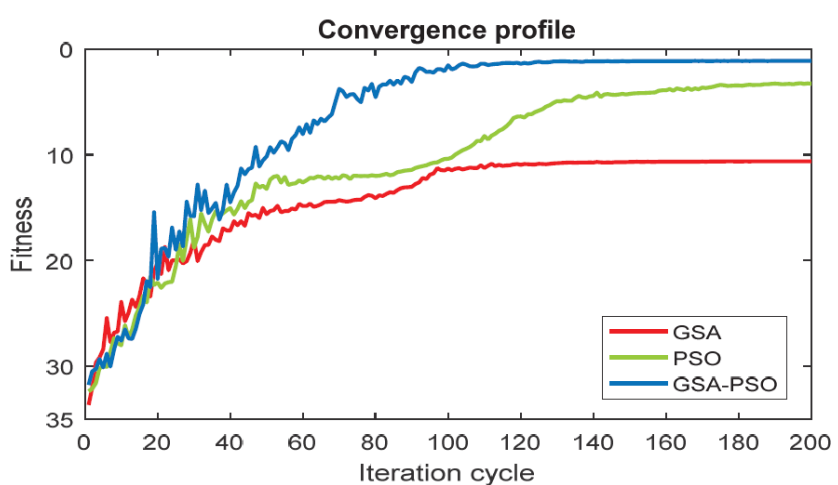

(a)

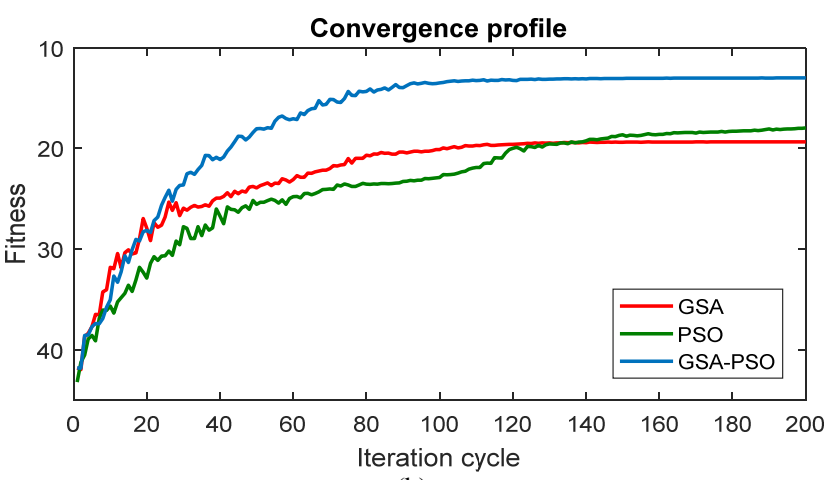

(b)

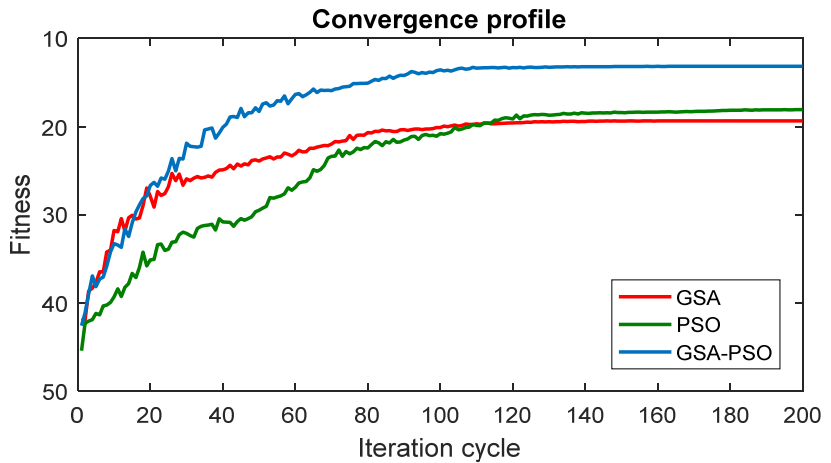

(c)

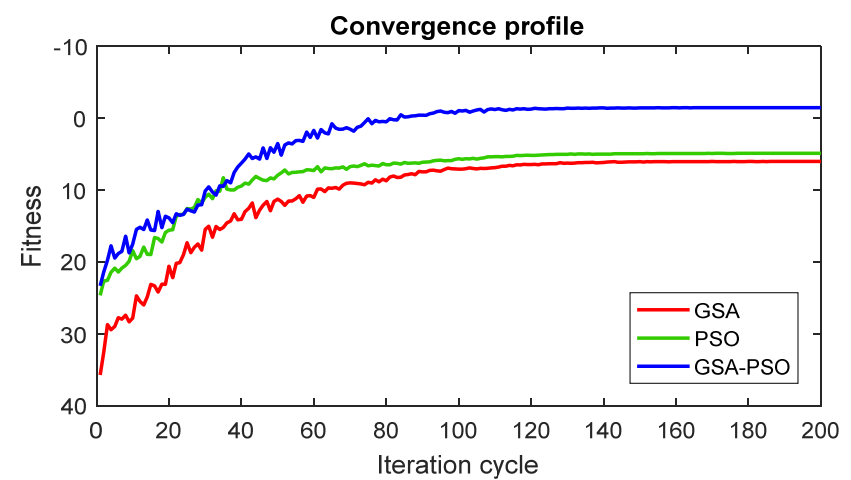

(d)

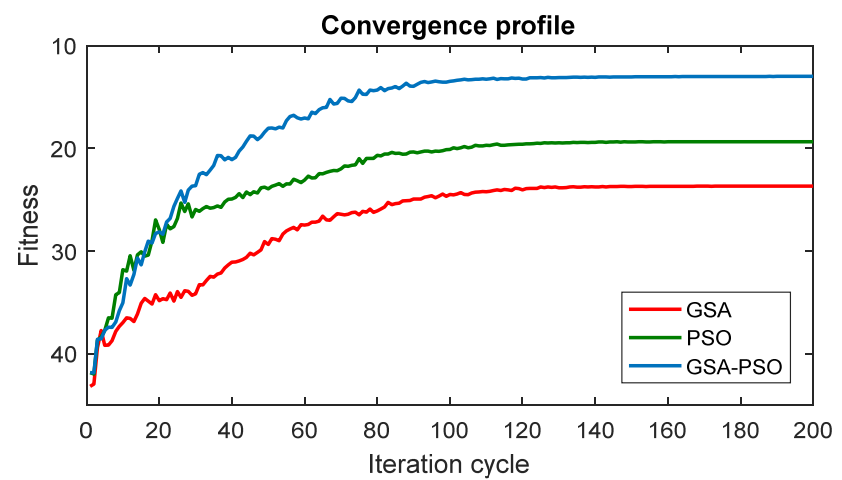

(e)

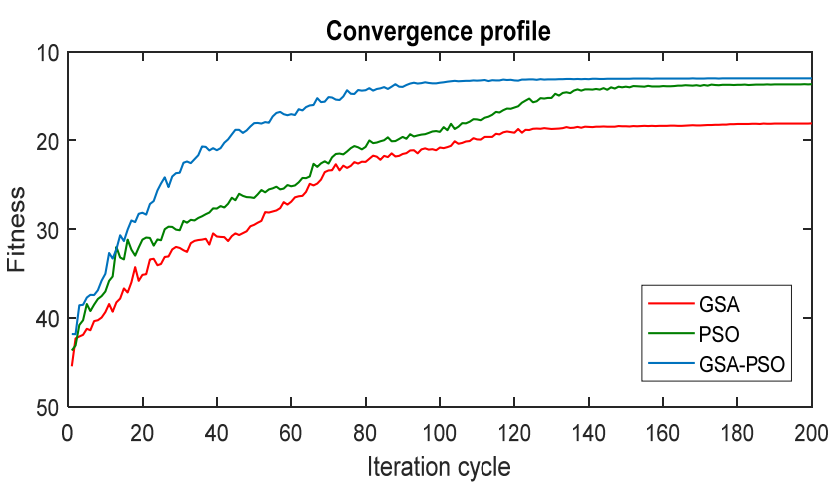

(f)

Fig. 4. Convergence profile for algorithms in case of nonuniform CCAA: (a) array-1, (b) array-2, (c) array-3, (d) array-4, (e) array-5, (f) array-6.

Intel (R) Core (TM) i5-4690 processor, $3.50 \mathrm{GHz}$ with 4 GB RAM. Figures $4(\mathrm{a}-\mathrm{f})$ show the superiority of hybrid GSA-PSO for minimizing the cost function for all cases.

\section{Conclusion}

For the optimization of complex, highly non-linear, discontinuous, and non-differentiable array factors of array antenna design, various heuristic search evolutionary optimization techniques have been applied. Evolutionary computation techniques are utilized to determine an optimum set of weights that create a non-uniform isotropic array that maintains SLL. Optimal thinning of CCAA of different sizes has also been investigated to generate a pencil beam with reduced SLL. Thinning an array to develop low side lobes is much simpler than handling the more general 
problem of non-uniform spacing of the elements. Nonuniform spacing has an infinite number of possibilities for locating the elements.

Percentage of thinning (number of OFF elements in percent) is more than $40 \%$ using GSA-PSO for almost all array sets. Higher value of array thinning gives less mutual coupling effect from the adjacent elements. Also, the cost and weight of the array is lower with higher value of thinning. Furthermore, CCAA using GSA-PSO not only gives the best SLL, radiation pattern using GSA-PSO gives the narrower main beam width (FNBW) among the three optimization algorithms in many cases. For simultaneous optimization of SLL and directivity, the characteristics being contradictory and this are modeled as a single objective optimization with suitable weighting factors for the objectives. There is future scope for multi-objective optimization for all the simulation works.

To optimize the design, the maxima of the single element and the array factor should both be directed toward $\theta_{0}=0^{\circ}$ (in our cases). In this paper, the requirements that allow the array factors to radiate broadside efficiently are developed. Considering $\theta_{0}=0^{\circ}$ and $\theta$ varying from $-90^{\circ}$ to $90^{\circ}$ with $\phi_{0}=90^{\circ}$ for maximum radiation. We can conclude that the overall extent of the visible region can be controlled by the inter-elemental spacing and its relative position on the unit circle by the progressive phase excitation of the elements. Both of these can be employed effectively for designing the array factors. It is considered as the future scope of present research work.

\section{References}

[1] BALANIS, C. A. Antenna Theory: Analysis and Design. WileyInterscience. $3^{\text {rd }}$ ed., 2005. ISBN: 0-471-66782-X

[2] KHODIER, M., AL-AQEEL, M. Linear and circular array optimization: a study using particle swarm intelligence. Progress In Electromagnetics Research B, 2009, vol. 15, p. 347-373. DOI: 10.2528/PIERB09033101

[3] IBRAHEM, S. M. M. Pattern synthesis of circular array. Computers \& Electrical Engineering, 1993, vol. 19, no. 3, p. 251-254. DOI: 10.1016/0045-7906(93)90006-D

[4] STEARNS, C., STEWART, A. An investigation of concentric ring antennas with low sidelobes. IEEE Transactions on Antennas and Propagation, 1965, vol. 13, no. 6, p. 856-863. DOI: 10.1109/TAP.1965.1138544

[5] HOltrup, M. G., MARGuinaud, A. CITERnE, J. Synthesis of electronically steerable antenna arrays with element on concentric rings with reduced sidelobes. In IEEE Antennas and Propagation Society International Symposium. Boston (MA, USA), 2001, p. 800-803. DOI: 10.1109/APS.2001.960218

[6] HAUPT, R. L. Optimized element spacing for low sidelobe concentric ring arrays. IEEE Transactions on Antennas and Propagation, 2008, vol. 56, no. 1, p. 266-268. DOI: 10.1109/TAP.2007.913176

[7] DESSOUKY, M. I., SHARSHAR, H. A., ALBAGORY, Y. A. Efficient sidelobe reduction technique for small-sized concentric circular arrays. Progress In Electromagnetics Research, 2006, vol. 65, p. 187-200. DOI: 10.2528/PIER06092503
[8] MANDAL, D., GHOSHAL, S. P., BHATTACHARJEE, A. K. Design of concentric circular antenna array with central element feeding using particle swarm optimization with constriction factor and inertia weight approach and evolutionary programing technique. Journal of Infrared, Millimeter, and Terahertz Waves, 2010, vol. 31, no. 6, p. 667-680. DOI:10.1007/s10762-010-9629-9

[9] DESSOUKY, M. I., SHARSHAR, H. A., ALBAGORY, Y. A. Optimum normalized-Gaussian tapering window for side lobe reduction in uniform concentric circular arrays. Progress in Electromagnetics Research, 2007, vol. 69, p. 35-46. DOI: 10.2528/PIER06111301

[10] DAS, S., MANDAL, D., KAR, R., et al. Nondominated sorting genetic algorithm-II based sidelobe suppression of concentric regular hexagonal array of antennas. In Proceedings of Swarm, Evolutionary and Memetic Computing Conference (SEMCCO2014). SOA University, Odisha (India), December, 2014 p. 697-705. DOI: $10.1007 / 978-3-319-20294-5$

[11] DAS, S., MANDAL, D., KAR, R., et al. Element spacing optimization of low sidelobe concentric hexagonal antenna arrays using MOEA/D. Intelligent Computing and Applications, Advances in Intelligent Systems and Computing, 2015, vol. 343, p. 189-196. DOI: 10.1007/978-81-322-2268-2-20

[12] GUNES, F., TOKAN, F. Pattern search optimization with applications on synthesis of linear antenna arrays. Expert Systems with Applications, 2010, vol. 37, no. 6, p. 4698-4705. DOI: 10.1016/j.eswa.2009.11.012

[13] ZARE, A. S., BAGHAIEE, S. Application of ant colony optimization algorithm to pattern synthesis of uniform circular antenna array. Applied Computational Electromagnetics Society Journal, 2015, vol. 30, no. 8, p. 810-818. ISSN: 1054-4887

[14] CHRYSSOMALLIS, M. Smart antennas. IEEE Antennas and Propagation Magazine, 2000, vol. 42, no. 3, p. 129-136. DOI: 10.1109/74.848965

[15] IOANNIDES, P., BALANIS, C. A. Uniform circular arrays for smart antennas. IEEE Antennas and Propagation Magazine, 2005, vol. 47, no. 4, p. 192-206. DOI: 10.1109/MAP.2005.1589932

[16] HAUPT, R. L. Thinned concentric ring arrays. In Proceedings of Antennas and Propagation Society International Symposium, AP-S 2008, p. 1-4. DOI: 10.1109/APS.2008.4619304

[17] MANDAL, D., GHOSHAL, S. P., BHATTACHARJEE, A. K. Application of evolutionary optimization techniques for finding the optimal set of concentric circular antenna array. Expert Systems with Applications, 2010, vol. 38, p. 2942-2950. DOI: 10.1016/j.eswa.2010.08.082

[18] DESSOUKY, M. I., SHARSHAR, H. A., ALBAGORY, Y. A A novel tapered beamforming window for uniform concentric circular arrays. Journal of Electromagnetic Waves and Applications, 2006, vol. 20, no. 14, p. 2077-2089. DOI: $10.1163 / 156939306779322701$

[19] SINGH, U., MUNISH, R. Design of thinned concentric circular antenna arrays using firefly algorithm. IET Microwaves, Antennas \& Propagation, 2014, vol. 8, no. 12, p. 894-900. DOI: 10.1049/iet-map.2013.0695

[20] CHAN, S. C., CHEN, H. H. Uniform concentric circular arrays with frequency-invariant characteristics mdash; theory, design, adaptive beamforming and DOA estimation. IEEE Transactions on Signal Processing, 2007, vol. 55, no. 1, p. 165-177. DOI: 10.1109/TSP.2006.882109

[21] HAUPT, R. L. Thinned arrays using genetic algorithms. IEEE Transactions on Antennas and Propagation, 1994, vol. 42, no. 7 , p. 993-999. DOI: 10.1109/8.299602

[22] SCHWARTZMAN, L. Element behaviour in a thinned array. IEEE Transactions on Antennas and Propagation, 1967, vol. 15, no. 4, p. 571-572. DOI: 10.1109/TAP.1967.1138989 
[23] RAZAVI, A., FOROORAGHI, K. Thinned arrays using pattern search algorithms. Progress in Electromagnetics Research, 2008. vol. 78, p. 61-71. DOI: 10.2528/PIER07081501

[24] BERA, R., ROY, J. S. Thinning of elliptical and concentric elliptical antenna arrays using particle swarm optimization. Microwave Review, 2013, vol. 19, no. 1, p. 2-7.

[25] PRATIHAR, K. D. Soft Computing. Alpha Science International Ltd, 2007. ISBN: 8184874952

[26] HUI, N. B., PRATIHAR, D. K. Camera calibration using a genetic algorithm. Engineering Optimization, 2008, vol. 40, no. 12, p. 1151-1169. DOI: 10.1080/03052150802344477

[27] HAUPT, R. L. Phase-only adaptive nulling with a genetic algorithm. IEEE Transactions on Antennas and Propagation, 1997, vol. 45, no. 6, p. 1009-1015. DOI: 10.1109/8.585749

[28] CHEN, K., HE, Z., HAN, C. A modified real GA for the sparse linear array synthesis with multiple constraints. IEEE Transactions on Antennas and Propagation, 2006, vol. 54, no. 7, p. 2169-2173. DOI: 10.1109/TAP.2006.877211

[29] CEN, L., SER, W., YU, Z. L., et al. An improved genetic algorithm for aperiodic array synthesis. In Proceedings of IEEE International Conference on Acoustics, Speech and Signal Processing. Las Vegas (USA), 2008, p. 2465-2468. DOI: 10.1109/ICASSP.2008.4518147

[30] MURINO, V., TRUCCO, A., REGAZZONI, C. S. Synthesis of unequally spaced arrays by simulated annealing. IEEE Transactions on Signal Processing, 1996, vol. 44, no. 1, p. 119-122. DOI: $10.1109 / 78.482017$

[31] RASHEDI, E., NEZAMABADI-POUR, H., SARYAZDI, S. GSA: A gravitational search algorithm. Information Sciences, 2009, vol. 179 , no. 13 , p. 2232-2248. DOI: 10.1016/j.ins.2009.03.004

[32] RASHEDI, E., RASHEDI, E., NEZAMABADI-POUR, H. A comprehensive survey on gravitational search algorithm. Swarm and Evolutionary Computation, 2018, vol. 41, p. 141-158. DOI: 10.1016/j.swevo.2018.02.018

[33] ING, K. G., MOKHLIS, H., ILLIAS, H. A., et al. Gravitational search algorithm and selection approach for optimal distribution network configuration based on daily photovoltaic and loading variation. Journal of Applied Mathematics, 2015, p. 1-11. DOI: $10.1155 / 2015 / 894758$

[34] CHAU, K. W. Application of a PSO-based neural network in analysis of outcomes of construction claims. Automation in Construction, 2007, vol. 16, no. 5, p. 642-646. DOI: 10.1016/j.autcon.2006.11.008

[35] EBERHART, R. C., SHI, Y. Particle swarm optimization: Developments, applications and resources. In Proceedings of the Congress on Evolutionary Computation. Seoul (South Korea), 2001, vol. 1, p. 81-86. DOI: 10.1109/CEC.2001.934374

[36] GIES, D., RAHMAT-SAMII, Y. Particle swarm optimization for reconfigurable phase-differentiated array design. Microwave and Optical Technology Letters, 2003, vol. 38, no. 3, p. 168-175. DOI: 10.1002/mop.11005

[37] ROBINSON, J., RAHMAT-SAMII, Y. Particle swarm optimization in electromagnetics. IEEE Transactions on Antennas and Propagation, 2004, vol. 52, no. 2, p. 397-407. DOI: 10.1109/TAP.2004.823969

[38] JIN, N., RAHMAT-SAMII, Y. Advances in particle swarm optimization for antenna designs: Real-number, binary, single- objective and multiobjective implementations. IEEE Transactions on Antennas and Propagation, 2007, vol. 55, no. 3, p. 556-567. DOI: 10.1109/TAP.2007.891552

[39] KENNEDY, J., EBERHARD, R. C. Particle swarm optimization. In Proc. of IEEE International Conference on Neural Networks. Perth (Australia), 1995, p. 1942-1948. DOI: 10.1109/ICNN.1995.488968

[40] EBERHART, R. C., SHI, Y. Parameter selection in particle swarm optimization. In Proc. of the 7th Annual Conference on Evolutionary Programming. 1998, p. 591-600. DOI: 10.1007/BFb0040810

[41] MALLICK, S., KAR, R., MANDAL, D., et al. Optimal sizing of CMOS analog circuits using gravitational search algorithm with particle swarm optimization. International Journal of Machine Learning and Cybernetics, 2017, vol. 8, no. 1, p. 309-331. DOI: 10.1007/s13042-014-0324-3

[42] KHAlEGHI, A., AZOUlAy, A., BOLOMEY, J. C. Diversity techniques with dipole antennas in indoor multipath propagation. In Proceedings of the IEEE 16th International Symposium on Personal, Indoor and Mobile Radio Communication. 2005, p. 669-673. DOI: 10.1109/PIMRC.2005.1651520

\section{About the Authors...}

Rajesh BERA received his B. Tech degree in Electronics and Communication Engineering, from Birbhum Institute of Engineering \& Technology, Birbhum, West Bengal, India in 2010. He received the M. Tech degree from Kalinga Institute of Industrial Technology, Bhubaneswar, Orissa, India in 2012. He has completed his PhD in the department of ECE, NIT Durgapur, India. Presently, he is working as Sr. Asst. Professor in the Department of ECE, Madanapalle Institute of Technology \& Science, Andhra Pradesh, India. His research interest includes array antenna design, array parameter optimization and beam-pattern synthesis using evolutionary computing techniques.

Krishanu KUNDU received his M.Tech degree in Embedded System Technologies from Anna University, Chennai in 2011 and received his B.Tech degree in Electronics \& Telecommunication Engineering from Pt. R.S.S.U University, Raipur in 2007. He is currently pursuing his $\mathrm{PhD}$ degree in Electronics \& Communication Engineering from Maulana Abdul Kalam Azad University of Technology, formerly known as WBUT. His main research interest is optimization of different types of antenna arrays using different bio inspired algorithms.

Narendra Nath PATHAK received his $\mathrm{PhD}$ degree from NIT Durgapur and is currently working as Professor and Head of Electronics \& Communication Engineering in Dr. B. C. Roy Engineering College, Durgapur, India. His main research interests are designing and optimization of different types of antenna arrays. He has published research papers in journals of repute like IEEE, JIMT and PIER. 